\title{
PROPIEDAD DE LA TIERRA INDÍGENA Y ALTERIZACIÓN EN EL TERRITORIO ANDINO FRONTERIZO. UN ESTUDIO DE CASO DE TICNAMAR, SIGLOS XVIII-XXI, NORTE DE CHILE*
}

\author{
Indigenous Land Ownership and Alterization in the Andean Frontier Territory. \\ A Case Study of Ticnamar Locality, XVIII-XXI Centuries, Northern Chile
}

\section{LESLIA VÉLIZ** ${ }^{\star}$ CRISTHIAN CERNA*** \& SHIRLEY SAMIT-OROZ***}

Fecha de recepción: 13 de febrero de 2019 - Fecha de aprobación: 17 de junio de 2019

\section{Resumen}

Este artículo describe aspectos de las diferenciaciones comunitarias asociadas a la regularización de la propiedad de la tierra indígena en Ticnamar, localidad de la precordillera de Arica, en el norte de Chile. Desde la revisión de su historicidad (siglos XVIII-XXI), se examinan las estrategias y las pugnas urdidas para ostentar la titularidad de la propiedad de la tierra y su correlato en la formulación de alterizaciones. Considerando el análisis de antecedentes documentales y de observación participativa, el resultado de las indagaciones permite afirmar una relación entre la configuración de la diferenciación sociocultural y la trayectoria seguida en las acciones para adquirir certidumbre jurídica sobre la propiedad de la tierra. La formulación de otredades indígenas de acuerdo a redes de parentesco ancladas al territorio fronterizo implica la instalación de intereses corporativos que reproducen antagonismos vinculados a la intervención del Estado en la frontera nacional y a sus clasificaciones étnicas.

Palabras clave: propiedad indígena de la tierra; comunidad andina; norte de Chile; clasificaciones sociales.

\begin{abstract}
This article describes aspects of community differentiation associated with arrangements for the regularization of the indigenous land ownership in Ticnamar, a locality in the precordillera of Arica at northern Chile. On the foundation of its historical background (XVIII-XXI centuries), we show the strategies and struggles conceived on the land property management and its correlate with the formulation of the local otherness. Considering the analysis of documentary and participatory observation sources, the result of the inquiries allows affirming a relationship between the configuration of sociocultural differentiation and the trajectory followed in the actions to acquire legal certainty about the land ownership. Formulating alterities according to kinship networks anchored with the frontier territory, this implies the installation of opposing corporate interests that reproduce antagonisms associated to the State intervention in the national border area, through the ethnic classifications, legitimacies and meanings with effects on self-understanding around to the territory and development.
\end{abstract}

Keywords: indigenous land ownership; andean communities; northern Chile; social classifications.

\footnotetext{
* Este artículo es resultado de los proyectos PLU 160025 (CONICYT), FCS-1405 (Facultad de Ciencias Sociales, Universidad de Chile) y FONDECYT № 1130667. Los autores agradecen al Programa de Capital Humano avanzado de beca de magíster nacional CONICYT (convocatoria 2014, Folio № 22140937), a la beca de magíster CONADI, y al programa doctoral BIO Fulbright-CONICYT, Becas Chile (convocatoria 2017, Folio № 56170005). Asimismo, agradecemos a los evaluadores sus valiosas observaciones y sugerencias, y a todos los participantes de este estudio en el pueblo de Ticnamar.

** Magíster en Antropología, Profesora de Historia y Geografía. Doctorante, Programa Postgrado en Antropología de la Universidad de Tarapacá-Universidad Católica del Norte, Arica, Chile. Correo-e: lesliaveliz@gmail.com

*** Encargado Macrozona norte, Propuestas País, Fundación Superación de la Pobreza / Magíster en Sociología, y Antropólogo Social. Becario doctoral BIO Fulbright, Becas Chile. Facultad de Ciencias Sociales, Universidad de Tarapacá, Arica, Chile. ORCID ID https://orcid.org/0000-0001-6117-2381. Correo-e: cristhiangcerna@gmail.com

**** Magíster en Género, e Historiadora. Profesional Servicio País, comuna de Alto Hospicio, Fundación Superación de la Pobreza, Tarapacá, Chile. ORCID ID https://orcid.org/0000-0002-7377-5005. Correo-e: shirleysamit@gmail.com
} 


\section{Introducción}

Recientes investigaciones antropológicas han señalado la importancia de sostener estudios sobre la propiedad de la tierra indígena por ser esta un dispositivo cultural, socioeconómico y político que involucra la formulación clave de contingentes locales, sus prácticas socioespaciales y el ejercicio de la gubernamentalidad (Baptista, 2018; Hann, 1998, 2007; Lavigne, 2018). La definición de arreglos de uso, apropiación, diferenciación y sucesión de la propiedad en relación con las redes de individuos y/o instituciones segmentarias y corporativas, permite comprender la configuración de los sistemas consuetudinarios, fundados en acervos de significados negociados en la dinámica de la imposición y la apropiación de recursos (auto)comprensivos en una biogeografía de referencia (Assies, Van der Haar \& Hoekema, 2002; Barth, 1976; Berraondo, 2006; Foucault, 2004; Goody, 1962; Krotz, 2002). En correlación con el modelo cultural de soberanía continua impuesto por el Estado, esta configuración asume desafíos novedosos para la promoción de los derechos territoriales e involucra la revisión de fenómenos asociados a la demanda de ciudadanías culturales y a las reclamaciones de autoafirmación respecto del desarrollo y sus clasificaciones de la otredad (Boccara, 2007; Johnson, 2010; Muñoz, 1999).

En los Andes, la definición de la propiedad raíz, entendida como una red de relaciones corporativas y alterizadas, es un elemento estructurador y performativo de la comunidad (trans)territorial e indígena actual (Isla, 2017, 1984; Izko, 1986). Su identificación y asimilación han ido adecuándose al impacto de los procesos globales de las épocas colonial y republicanas -tempranas y tardías- (Albó, 1979; Abercrombie, 2006;
Casaverde, 1985; Izko, 1986; Salomón, 1991; Sendón, 2006, 2012; Ossio, 1992). Esto trajo como consecuencia la formación de memorias colectivas "situadas", fundacionalmente, en "pueblos" -o unidades socioterritoriales resultantes de las reformas toledanas (siglo XVI)- y de dimensiones de endodesarrollo demarcadas por un conjunto de procesos de (des)estructuración de espacios de ocupación ancestral catalogados, desde el siglo XIX en adelante, como nacionales (Abercombrie, 2006; Arana, 2014; Castro, 1997, 2006; González \& Ruz, 2015; Larson, 2002; Platt, 1982).

Tras la Guerra del Pacífico (1879), el Estado chileno anexó las actuales regiones del extremo norte. Con ello, se instaló un régimen de propiedad raíz liberal, que transformó los principios de titularidad y tenencia indígenas de la tierra, resguardados hasta entonces por el reconocimiento de la figura colectiva de las comunidades mediante lo que se llamó el "pacto colonial" (Gundermann, 2003; Ruz \& González, 2014; González, Gundermann \& Hidalgo, 2014; González \& Gundermann, 1997, 2009). Con esta nueva normativa se desconocieron las lógicas consuetudinarias y los arreglos con base en el parentesco para el saneamiento del bien raíz (Castro, 1997, 2001, 2006; Castro \& Bahamondes, 1987, 1988).

Al admitir solo la propiedad individual y a "contra papel", se buscó la adición de tales recursos al mercado de tierras. Para ello se fijó, como procedimiento necesario, la inscripción o reinscripción de las propiedades en el Conservador de Bienes Raíces con base en la documentación producida en los períodos anteriores (Gundermann, 2003; Ruz \& Gálvez, 2003). Con objeto de resguardar sus espacios de ocupación histórica, el trámite de la inscrip- 
ción de la tierra tuvo una alta convocatoria indígena. Para conservar sus propios espacios de sentido, estos contingentes elaboraron estrategias legales que respondieron creativamente a los parámetros establecidos (Barros, 2008). Los casos que no acreditaron titularidad fueron reputados como dominio fiscal. En Arica, ámbito que interesa revisar en este artículo, esta acción del fisco tuvo como hito el año 1935, en el que se realizó una inscripción global del entonces territorio departamental (González \& Gundermann, 1997, 2009; Véliz, 2014).

En el siglo XX se dieron procesos de asimilación y pauperización del espacio territorial indígena rural que han desembocado, en la actualidad, en una situación de progresivo despoblamiento. La pérdida estructural de resiliencia económica y la subsecuente radicación de dos tercios de sus miembros en las ciudades litorales de Arica e lquique (González, 2007; Gundermann, 2003, 2005) han Ilevado a que las comunidades locales formulen una doble articulación con el territorio -según la perspectiva planteada por Abercrombie (2006). Una de las estrategias de mantención de relaciones con el lugar de origen fue el acceso a la propiedad de la tierra (González \& Ruz, 2015). Se instalaron acciones para su regulación ante los sistemas impuestos de certidumbre jurídica y la adopción de lenguajes escritos que sirvieron, además, como elementos de autolegitimación, reinvención de la memoria colectiva y/o argumentación de la propia legitimidad/afirmación de la presencia histórica (Samit, Cerna \& Chávez, 2014). Esto implicó la reformulación de los orígenes colectivos y la implementación de sistemas consuetudinarios ad hoc que actuaron, de manera paralela, en la definición de la circulación de la propiedad de la tierra y en la perpetuación de esferas propias de interacción comunitaria asociadas a la unidad de pueblo (Castro, 2006; Cerna, Samit-Oroz \& Véliz, 2018; Ruz, 2005).

En la década de 1990, en el marco del trabajo de la Comisión Especial de Pueblos Indígenas (CEPI) para la formulación de la Ley 19.253 (año 1993), son encargados estudios catastrales a universidades, consultoras y organizaciones no gubernamentales (ONG), que caracterizaron aspectos antropológicos y jurídicos de la propiedad de la tierra indígena (González \& Gundermann, 1997, 2009; Pedrero, s.f. $)^{1}$. Desde entonces, se comprenden tipos específicos de comunidades de tierras -sucesorial, comunitaria, patrimonial e individual-, en torno a los que se formulan contingentes de interés, que instalan arreglos sucesorios coherentes con la tramitación positiva de la propiedad raíz en las áreas de valles litorales, precordillerana y altiplánica (Gundermann, 1998, 2005)².

Con ello se abrió, desde ámbitos académicos, privados, públicos y ciudadanos, una agenda sobre la materia que implica la instalación de nuevos análisis a partir de casos y abordajes históricos y etnográficos. Resulta importante discutir la naturaleza del conflicto por el acceso a la propiedad de la tierra y el territorio por su carácter de espacios multiculturales y de etnogubernamentalización (Boccara, 2007; Hale, 2004). Cabe documentar, en ese escenario, cómo se construyen las clasificaciones sociales y las alterizaciones en torno a campos de (re)producción de legitimidades, visibilidad y relaciones de (a)simetría con el Estado y su espacio específico de interacción y producción de actores.

Desde una perspectiva histórica que aborda de forma esquemática la temporalidad del 
fenómeno (siglos XVIII-XXI), este artículo describe las diferenciaciones y los conflictos comunitarios asociados a los arreglos relativos a la regularización y la titularidad de la propiedad de la tierra indígena en Ticnamar, localidad de la precordillera de Arica, en el extremo norte de Chile. Este asentamiento, ubicado a $130 \mathrm{~km}$ de la ciudad litoral de Arica y a 3.200 msnm, en el sector rural de la región homónima (Figura 1), cuenta con una alta autoadscripción indígena ${ }^{3}$. En este contexto, se plantea como hipótesis que la emergencia de estas colectividades basadas en un arraigo local permite la reproducción sociocultural de la comunidad andina desde una matriz sincrética y fundada en principios de cambio y continuidad de sus fundamentos institucionales relativos a las redes de familias. Estos principios sintetizan los conflictos internos asociados a la pugna por la titularidad de la tierra. Asimismo, se propone que el régimen de propiedad, en clave etnogubernamental y liberal, configuró procesos tanto de cohesión como de conflicto territorial. Estos posibilitaron la elaboración de alterizaciones desde una progresiva diferenciación y exclusión de las personas, que gatillaron etnicidades divergentes entre los miembros ticnameños.

Para este objeto, se formuló una investigación documental sobre el litigio de la titularidad de la propiedad raíz. Seguidamente, se desarrolló un muestreo estructural representativo con orientación en historias de vida y en la dimensión genealógica para complementar la comprensión de las pautas locales de diferenciación sobre la tierra. Se entrevistaron en profundidad a 15 actores claves autoidentificados como aymaras y pertenecientes a las redes de familias del territorio (seis mujeres y nueve hombres, de 60 a 80 años), para lo cual se siguió el criterio de debido consentimiento informado. Se sistema- tizó, además, una observación participante de tipo multisituada, tanto en la ciudad de Arica como en la localidad de Ticnamar, desde 2005 a 2017.

El artículo se estructura de la siguiente manera. Primero se describe la formación social de la propiedad y el conflicto histórico-sucesorial respecto del bien raíz (siglos XVIII-XXI). Luego, se expone un análisis de la situación actual de la titularidad de la tierra y su conflictividad, destacando aspectos de sus entidades de referencia. Tras esto, se establece una discusión en torno al acceso de la tierra y la formulación de la colectividad local, y, para concluir, se anotan las observaciones de síntesis.

\section{Formación histórica de la propiedad de la tierra indígena en Ticnamar}

En el siglo XVIII, el pueblo de Ticnamar procuró el resguardo jurídico de los derechos colectivos sobre su territorio (Figura 1). Estos fueron adquiridos a través de una escritura datada en $1758^{4}$. Desde entonces Diego Apasa "por sí y en representación del Común de Indios del pueblo de Ticnamar"5 adoptó la titularidad de "tres guaicos 6 Putaba, Achola y Tumaya", vendidos por unos "criollos" de Codpa:

Sepan cuantos esta casta bieren como nos Antonio Belasco y Lucas Madueño, besino del Pueblo de Codpa, otorgamos y conocemos por la presente carta que bendemos y damos en benta rial desde ahora para en todos tiempos y siempre jamás, al común de indios del pueblo de Tignamar, y en nombre de dicho Diego Apasa, indio principal, de dicho Pueblo quien está presente al otorgamiento de esta escritura para su aceptación es asaber, tres Guaicos de tierra nombradas Achola, Tumaya y Putaba ${ }^{7}{ }^{8}$ 
Debido a que la compraventa no era el último procedimiento para constituir propiedad, en 1773 los miembros locales solicitaron un traslado a través de una copia del documento, con lo que quedó inscrito en el pueblo de San Pedro de Tacna. Ello da cuenta de la importancia del dominio como elemento de prolongación comunitaria. Esto generó, desde épocas tempranas, diversas estrategias tendientes a la diferenciación local ${ }^{9}$ y a la conversión escrita de la memoria. El pueblo aparece como unidad de identificación y de ordenamiento jurídico-consuetudinario de las relaciones. Este último está basado en la legitimización de un orden sociopolítico implícito, encabezado de manera figurativa por Apasa y su genérico "común de indios".
En este plano se hace notar la complementación de los sistemas jurídicos positivos y consuetudinarios en la formulación de una agencia social de las comunidades que buscan una certidumbre jurídica de su bien raíz. Primero, opera a nivel formal, es decir, en el impuesto por los parámetros de los registros de propiedad "contra papel" y que los colectivos supieron sortear. Segundo, al mantener un sistema de relaciones basado en la costumbre y la comprensión exclusiva de los miembros de la comunidad, que actuó en la trayectoria de la formalización y la reproducción de la propiedad raíz como propia, en un contexto de negociación, complementación y dialécticas locales.

Figura 1: Localización de la propiedad de Ticnamar

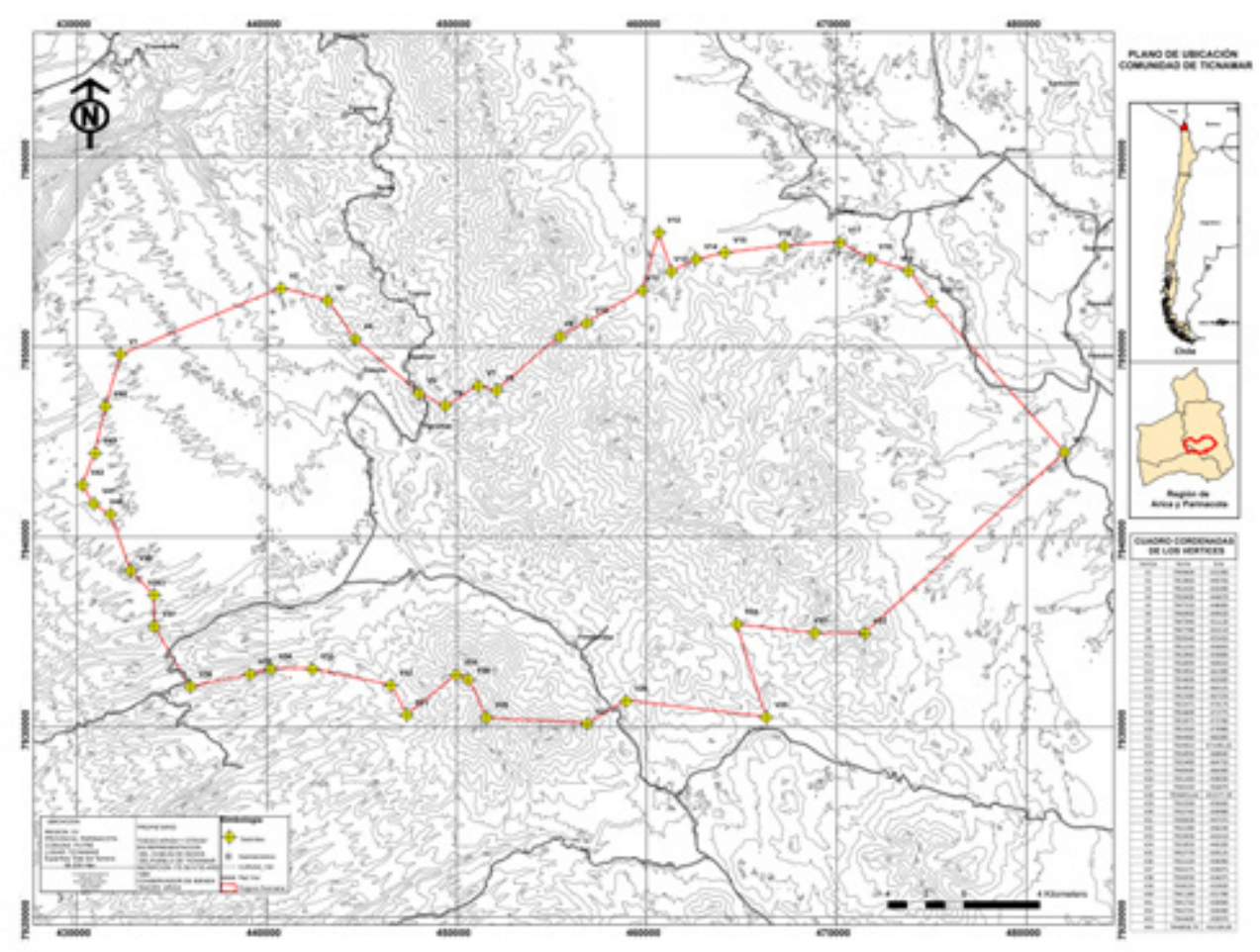

Fuente: Elaboración propia según la demarcación señalada en el documento Fs 56 №55, año 1994, Inscripción "Diego Apasa y otros en representación del común de indios del pueblo de Ticnamar", Conservador de Bienes Raíces de Arica. 
En el período colonial fue necesaria la transferencia física de la propiedad, la cual se realizó a través de una ceremonia de entrega en 1773. Ahí se les dio una copia de la escritura a los originarios del pueblo de Ticnamar (Véliz, 2014). En ese documento se menciona la personería de algunos comuneros en exclusivo, lo cual se volvió un hito relevante de vínculo con el común de indios. Entre los identificados se menciona a Ramón Ascles (Alcalde ordinario de Ticnamar), Martín Santiago, Bentura Apasa, Juan Mena y Felipe Apasa, "Indios originarios de dicho Pueblo de Tignamar en los y en nombre de todos los demás del comun de Indios [...] lo provo [sic] y mando y firmo y el General D. Demetrio Egan"10.11 llario Marca, juez comisionado del corregidor de Arica, sostuvo lo siguiente sobre este acontecimiento: "pase en compañía de toda la comunidad de la bise parroquia de Tignamar á [sic] quienes les doy posesión, y le hago conocer sus pertenencias y les enseñe en la lengua Aimara todo su contenido y hordenado por dicho $\mathrm{Sr}^{\mathrm{\prime}}{ }^{12}{ }^{13}$

Hasta 1856 existió una continuidad en el dominio del común de indios. Ese año, se transcribió la compraventa para dejar una copia en manos de los comuneros. Tal acto reveló una estrategia jurídica para resguardar el derecho colectivo en pugna, como señala la cita del documento en cuestión:

En este Pueblo de Tignamar [...] yo el Juez de Paz Anselmo Guzman yse copiar el presente título de su original esta algo rotoso y afin no se pierda sus letras puse conserto y se traslado sin quitar ni añadir una sola palabra y para su constancia se guardaran ambos papeles para que en lo sucesibo podamos defendernos y es fecho en dicho dia mes y año ante los testigos que presentes se allaron Romualdo Flores, Juan Tarque y Martin Ibañes, y yo suplique al Escribiente lo firmase por mi Ruego de Juez de Paz Anselmo Guzman y como Testigo Cosmelio Zavala ${ }^{14}$.

Luego de pasar por diferentes procesos legales, adscritos al sistema colonial y republicano temprano del Perú, se generaron estrategias para conseguir una mayor certidumbre de la ocupación, a través del pago de contribuciones ${ }^{15}$. Esto sirvió, a su vez, para fijar la memoria de los miembros originarios del territorio y su tenencia continua (González, Gundermann e Hidalgo, 2014; Inostroza, 2017).

Posteriormente, a inicios del siglo $\mathrm{XX}$, en la administración chilena, se produjo la protocolización de la compraventa. Conforme a la instalación de un sistema de propiedad raíz que desconoció las entidades colectivas detentoras de derecho privado, en 1903 se protocolizó el título de compraventa $(1758)^{16}$ por seis comuneros: Vicente Flores, Bartolomé Zubieta, Mariano y Juan de la Cruz Yucra, Rudecindo Apaz y Toribio Ponce, en representación de la comunidad y en referencia a la categoría de poseedores de unos terrenos legados de sus ancestros. Posteriormente, se inscribió en el Conservador de Bienes Raíces de Arica en 1909, manteniendo la titularidad de la compraventa de 1758 (Figura 2). 
Figura 2: Diego Apaza, el común de indios y los primeros miembros detentores de herencia y sucesorios, y las comunidades configurantes (modelo de síntesis) ${ }^{17}$.

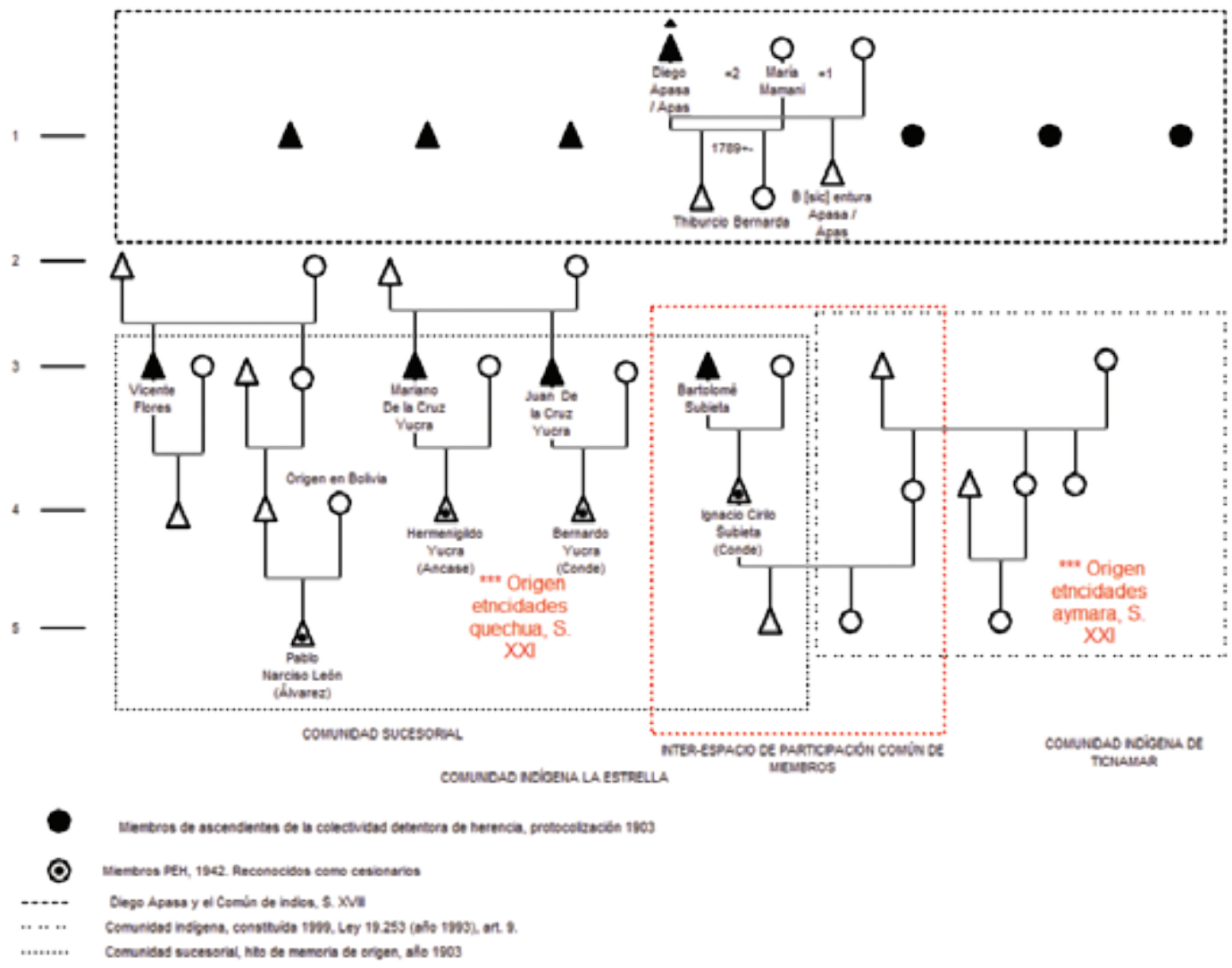

Fuente: Elaboración propia.

En 1941 se interpuso una solicitud de posesión efectiva ${ }^{18}$ en referencia a la protocolización de 1903. A través de la conformación de una colectividad detentora de herencia, figura en torno a la cual se agrupó un contingente de actores que demandó derechos de titularidad sobre la propiedad de la tierra, se fue configurando un arreglo sucesorio respecto de la propiedad. De esta forma, los detentores de herencia presentaron la escritura pública como título de dominio de los causantes, es decir, de los seis comuneros comparecientes en 1903 y ya fallecidos en 1941, de los que declararon descender y ser sus exclusivos descendientes.
Aquello supuso la adición de elementos de conflictividad a las relaciones intracomunitarias. Debido a la complejización del estatus de participación en la dinámica de la propiedad de la tierra y la emergencia de expectativas de apropiación individual, los solicitantes indicaron que los causantes ${ }^{19}$ eran poseedores de un predio denominado comunidad de Ticnamar, al que incluyeron en un inventario simple de los bienes de la herencia. Este acompañó, como respaldo, la escritura pública de 1903 -obviándose la inscripción conservatoria de 1909. Ello implicó la intención de actuar como poseedores jurídicos únicos, relativizando la figura del común de indios. 
En 1942, el Tribunal de Arica otorgó la posesión efectiva (PEH) a cuatro solicitantes. En $1944^{20}$, estos reinscribieron los terrenos del común de indios de Ticnamar y la nueva inscripción quedó a título de Diego Apasa y dicho común de indios. Por consiguiente, no se realizó la inscripción especial de herencia a nombre de los herederos. Con ello, la colectividad local mantuvo el consenso en su formulación global como entidad socioterritorial como hito en la elaboración de imaginarios vinculados a la trayectoria escrita de la propiedad raíz. Paralelamente, se manifestaron procesos de diferenciación externa e interna, en los que Ticnamar siguió la trayectoria de pauperización del territorio indígena que gatilló, desde la década de 1960, una emigración masiva ${ }^{21}$ (Carrasco, 2016; González, 2016; Grebe, 1997), así como la participación en los modelos de modernización regional que imprimían el paradigma de "progreso". En esta época, considerando la observación de un periódico local de Arica sobre el pueblo, se visualiza el siguiente parámetro de desarrollo:

Después de un largo período de desesperanzas, florece allí el optimismo y la fe en el futuro. Región esencialmente ganadera tiene también muy buenos productos de chacarería [...] La acción de varias organizaciones ha permitido que el lejano pueblo de Ticnamar empiece a caminar con paso decidido por la ruta del progreso, con renovada confianza en el porvenir [...] Ticnamar fue un pueblo arruinado por continuas avenidas. Una de estas se llevó en una oportunidad la mitad del pueblo y puso en peligro la vida de sus habitantes. Las autoridades consideraron entonces la necesidad de cambiar el pueblo a un sitio más protegido. Hace cinco años ocurrió el cambio a una explanada más alta y el pueblo cambió de fisonomía. Su aspecto característicamente colonial se conserva en las pocas calles del pueblo viejo ${ }^{22}$.
Por entonces se agudizó la fragmentación de las tierras, proceso iniciado a comienzos del siglo XX. Se partió con la inscripción de chacras particulares, a manera de estrategia de certidumbre jurídica para los comuneros, pero sin contravenir la dimensión de derecho colectivo. Luego se incorporó el Decreto Legal 2.695 (1979), que implicó el acceso a la regularización a través de la figura de pequeña propiedad raíz, a partir de la cual se fueron constituyendo dominios de predios.

Se suscitaron, además, nuevos factores que agregaron elementos de complejidad a las lógicas comunitarias ancladas en la figura de Diego Apasa y el común de indios (Véliz, 2014). Esta figura, que mantuvo su capacidad de aglutinar a los miembros locales en torno a un proceso en común, fue modulando los faccionalismos emergentes, a partir de lo cual se reprodujeron, dialécticamente, redes de solidaridad y antagonismo, basadas en el parentesco y la memoria local. Tal nodo crítico posibilitó la conformación de un ethos ${ }^{23}$ de naturaleza corporativa y con capacidad de reproducción, que, más allá de los conflictos contingentes, soportó la adscripción local en la noción de "ticnameños/as", en mención a los vínculos que establecen los actores con el espacio geográfico imbuidos por un sentimiento de pertenencia socioterritorial (Barth, 1976; Gavilán, 2016). Si bien esto es relevante, dado el cambio de perfil de los miembros, por su desplazamiento de un espacio microrregional a otro regionalizado y translocal (González y Gundermann, 2009), también lo es la incorporación de otros elementos colaterales de diferenciación, como la clasificación de los miembros con ocupación efectiva y virtual -ya radicados en Arica u otro centro regional. 
Siguiendo la tabla 1, podemos advertir cronológicamente el fenómeno. Dada la conformación de los procesos locales y el regional, cabe observar que, desde la constitución de la figura sociojurídica de Diego Apasa y el común de indios (1758), se gatilla un campo específico de relaciones comunitarias. Esta identificación adopta, en su composición, principios de intereses en progresiva oposición entre los grupos locales (período 1758-1903). Así, a inicios del siglo $\mathrm{XX}$, la figura del común de indios da paso a la de la comunidad local y a su oposición, es decir, la denominada "colectividad detentora de herencia". A partir de estas dos entidades se instituye un pleito legal por la búsqueda de recursos privativos que permitan la certidumbre y la capitalización de la detención de derechos de acceso a la tierra (período 1941-1979). Esta situación se mantiene durante el gobierno militar, momento en que se da una mayor fragmentación de la dimensión reproductiva de la comunidad vía la ejecución del Decreto Ley 2.695 (1979).

Posteriormente, con el retorno a la democracia en el país y la emergencia de la política pública indígena, las diferenciaciones étnico-jurídicas, en clave de pueblos aymara y quechua, toman nuevas pautas, ahora vinculadas a un proyecto de pueblos indígenas regionales en un escenario de incremento exponencial de la complejidad de la sociedad y de transformación de la vida colectiva. Siguiendo a Gundermann (2001), esto se expresa en la diversificación de espacios colectivos, la multiplicación de nexos y de relaciones individuales y sociales, así como en la transformación radical de la comunidad local en una comunidad translocal y supralocal, que traspasa las fronteras efectivas del territorio comunitario concreto. Con ello se complejizan las instituciones y referentes organizativos y emergen nuevos actores con visiones globalizadas. En esta fase van a tomar protagonismo, en la prolongación del pleito, las formaciones organizativas de la comunidad sucesorial y de la comunidad indígena (período 1995-actualidad). Estas entidades adoptan nuevos marcos referenciales de sentido asociados a la expansión de los campos de significado que afectan su proyección regionalizada, lo que generará nuevas modalidades en la dinámica (re)productiva de la comunidad ticnameña (Tabla 1). 
Tabla 1: Síntesis cronológica de algunos hitos del conflicto por la propiedad y de las entidades colectivas correlativas, siglos XVIII-XXI ** Estos documentos tienen carácter público.

COLECTIVIDADES

\begin{tabular}{|c|c|c|}
\hline & & a vecinos "criollos" de Codpa, el \\
\hline & & $\begin{array}{l}\text { *** Revisita } 1750 \text { (Hidalgo, 1978, p. 83). Alusión a Diego Apasa/Apas y familia nuclear, en } \\
\text { categoría de reservado (sin pago de tributo, por edad). Esta definición, probablemente, está } \\
\text { relacionada con que Diego tuvo otros hijos/as que en el momento eran mayores de edad y, } \\
\text { por tanto, que no estaban registrados en su membresía. }\end{array}$ \\
\hline & & $\begin{array}{l}\text { *** Revisita } 1773 \text { de Codpa (Altos de Arica) (Hidalgo, Castro y González, 2004), alusión a } \\
\text { Ticnamar y los grupos locales. }\end{array}$ \\
\hline$\stackrel{\cdot \frac{0}{0}}{.}$ & & $\begin{array}{l}\text { 1773, Toma de posesión / Traslado de copia de compraventa y adquisición de dominio de } \\
\text { bien raíz Ticnamar. }\end{array}$ \\
\hline$\stackrel{x}{x}$ & & ${ }^{* * *}$ Padrón de la doctrina de Belén en 1813 (Hidalgo et al., 1988) \\
\hline$\equiv$ & & 1856, Transcripción de la compraventa de 1758 en Ticnamar. \\
\hline $\begin{array}{l}x \\
\text { 음 } \\
\frac{0}{\infty}\end{array}$ & & $\begin{array}{l}\text { 1903, Protocolización de copia de título de dominio de } 1856 \text { (original 1758) en Arica. Se fija } \\
\text { la memoria sucesorial desde: Vicente Flores, Bartolomé Subieta, Mariano y Juan de la Cruz } \\
\text { Yucra, así como Rudecindo Apaz y Toribio Ponce. }\end{array}$ \\
\hline & & 1909, Inscripción de la escritura pública de protocolización de 1903 en Arica. \\
\hline & & $\begin{array}{l}\text { 1927, Juicio de reivindicación de Comunidad de Ticnamar y Juan de la Cruz Yucra (Yucra } \\
\text { inscribe un predio en el Conservador de Bienes Raíces [CBR]). Se reestablece la propiedad } \\
\text { a la comunidad. }\end{array}$ \\
\hline & & $\begin{array}{l}\text { 1927, Inscripción de Predio La Estrella, por juez de distrito Graciano Bernal. Posterior } \\
\text { compraventa de familia Sajama. }\end{array}$ \\
\hline = & & $\begin{array}{l}\text { 1941, Acto de solicitud de posesión efectiva de herencia (PEH) a nombre de seis comuneros } \\
\text { según el documento de } 1903 \text { (obviando el de 1909). }\end{array}$ \\
\hline 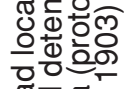 & $\underset{x}{x}$ & $\begin{array}{l}\text { 1942, Tribunal de Arica otorga auto PEH a cuatro comuneros: Hermenegildo Yucra Ancase, } \\
\text { Bernardo Yucra Conde, Ignacio Cirilo Zubieta y Pablo Narciso León Álvarez. }\end{array}$ \\
\hline 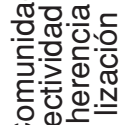 & $\frac{\circ}{\mathrm{O}}$ & $\begin{array}{l}\text { 1944, Se reinscribe el título de propiedad (en base al título de 1909), en Arica. Y negación de } \\
\text { inscripción de PEH por parte del Conservador Fs } 56 \text { № } 55 \text { del Registro de Propiedad del año } \\
1944 \text { CBR Arica, requerida por Hermenegildo Yucra Ancase, como "heredero cabeza del grupo". }\end{array}$ \\
\hline ن잉 & & $\begin{array}{l}\text { 1979, Decreto Ley } 2695 \text { ( } 21 \text { de julio). Posesión de pequeña propiedad raíz para constitución } \\
\text { de dominio de predios agrícolas. }\end{array}$ \\
\hline & & $\begin{array}{l}\text { ** 1999, Otorgamiento personalidad jurídica a la comunidad indígena aymara de Ticnamar } \\
\text { (Ley 19.253, año 1993)/1998, Otorgamiento personalidad jurídica a la comunidad indígena } \\
\text { aymara de La Estrella. }\end{array}$ \\
\hline 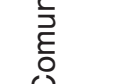 & & $\begin{array}{l}\text { ** } 2000 \text {, Rescate de título de propiedad de } 1909 \text { y } 1944 \text {, Archivo Nacional. ** El universo } \\
\text { mayor de la comunidad local desconocía desde } 1944 \text { este documento. }\end{array}$ \\
\hline 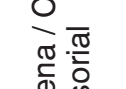 & $\begin{array}{l}\bar{x} \\
\grave{x} \\
\dot{x}\end{array}$ & $\begin{array}{l}\text { 2005, Inscripción de acciones y derechos de la comunidad sucesorial, designación de adminis- } \\
\text { tración pro-indivisa. ** Surgimiento de comunidad sucesorial como entidad de interés particular. }\end{array}$ \\
\hline 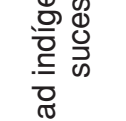 & $\frac{x}{\infty}$ & $\begin{array}{l}\text { 2007-2014, Sentencia Juicio de Reivindicación (expediente rol № 639-2007), reconoce } \\
\text { herederos a comunidad sucesorial y otorga reconocimiento de posibles herederos a otros } \\
\text { comuneros (alusión a Ley 19.253). }\end{array}$ \\
\hline 을 & & $\begin{array}{l}\text { 2014, Sentencia recurso de protección que reconoce ancestralidad a la comunidad indígena } \\
\text { aymara de Ticnamar (C169 OIT). Rol 37-2014. } \\
\text { ** Fenómeno de emergente complejidad pos } 2014 \text {, asociado a la dimensión jurídica-consue- } \\
\text { tudinaria y apropiación-elaboración de organizaciones territoriales y funcionales. }\end{array}$ \\
\hline
\end{tabular}

Fuente: Elaboración propia según análisis de documentación de tramitaciones 


\section{Aspectos de la conflictividad social por la titularidad de la propiedad}

Ainicios de la década de 1990, en un escenario de instalación de políticas sociales especializadas en materias indígenas (a través de la Ley 19.253, año 1993) y de retorno a la democracia, la colectividad resultante del conflicto jurídico reformuló la pugna y su diferenciación se orientó en dos entidades aglutinantes de la oposición por los derechos de la tierra. Un actor entrevistado advierte sobre esta alterización y su correlato en la formación de organizaciones funcionales al Estado:

Entonces formaron la comunidad indígena [según la ley], y estos caballeros [la otra comunidad, la sucesorial, es decir, la comunidad de tierra resultante de una de las partes del litigio] formaron otra personalidad jurídica indígena como comunidad [indígena]. Pero, arriba no hay vivientes, vive un pastor nada más. Ahora nosotros estamos haciendo los trámites para inscribirle como comunidad indígena; ahora, ellos no están de acuerdo, porque dicen que el Estado un día les van a quitar esas tierras (Actor, masculino, Ticnamar, 2001).

Las entidades resultantes internalizaron los cambios del proceso previo e incorporaron nuevos pliegues al desencuentro comunitario (Figura 3). Por un lado, en el marco de la nueva institucionalidad indígena, a fines de la década de 1990, un segmento de los miembros de la comunidad sucesorial constituyó la comunidad indígena aymara de La Estrella (afiliada a la comunidad sucesorial). Por el otro lado, los otros comuneros, vinculados a la comunidad local, generaron los arreglos para constituir la comunidad indígena aymara de Ticnamar. Vemos cómo en estos dos grupos se proyecta la distinción interna que existe respecto de los otros formatos territoriales y funcionales del territorio y de la región. La comunidad sucesorial con ascendencia en la colectividad detentora de herencia, surgida en 2005 a partir de la inscripción de acciones y derechos, fue tomando centralidad para quienes se vinculan con esa falange. Algunos de sus miembros fueron mostrando una tendencia al reconocimiento complementario de la adscripción quechua y formulando organizaciones en el contexto de la institucionalidad indígena ${ }^{24}$.

En pugna con versiones encontradas en torno a la etnogénesis de Ticnamar, estos formatos participativos han sido centrales para la elaboración, "textualización" y performativa de la memoria alterizada, en el sentido propuesto por Abercrombie (2006) y Salomon (1991). Visto de esta forma, sus miembros y adherentes se fundamentan en la sistematización de antecedentes documentales (históricos, judiciales y técnicos, elaborados por especialistas y/o la institucionalidad pública), orales y prácticas socioculturales indígenas para formular relatos autovalidantes y egocéntricos de sus propios arraigos segmentarios con respecto del territorio, a los que suman sentidos étnicos y la reclamación exclusiva de la propiedad raíz ${ }^{25}$. Con todo, ambos, la entidad indígena aymara y la sucesorial, comprenden, como criterio principal, la descendencia asociada al pueblo. Apelan, así, a una justificación desde su existencia ancestral y a la demanda por el territorio como unidad de propiedad colectiva y/o individual.

De acuerdo a lo mencionado, al advertir la figura 3 podemos notar que el fenómeno ha tenido dos flancos concurrentes de complejidad. El primero, que denominaremos territorialidad, está relacionado con la matriz sociocultural fronteriza de negociación étnica y la territorial, desde donde se elabora la pertenencia con el lugar de identificación, su contexto colonial/ 
nacional y su horizonte de escalamiento asociativo y estratégico en materias del desarrollo e inversión. Esto sucede bajo el amparo de las propias negociaciones microhistóricas de los miembros con la sociedad mayor y sus innovaciones organizativas desde el marco consuetudinario e institucional, que resguarda el acervo básico de diferenciación general en cuanto ticnameños. El segundo ámbito, que denominaremos propiedad de la tierra, comprende un campo gubernamentalizado con clasificaciones excluyentes, basado en criterios de progresiva adición de elementos liberales y de derecho positivo que refuerzan la importancia de la certidumbre jurídica basada en el documento escrito y la noción de corporativismo segmentario. En este último plano, las comunidades se han escindido desde la compraventa, pasando por el modelo cacique y común de indios, el de la comunidad y la colectividad detentora de herencia, hasta las figuras de intereses opuestos de la comunidad sucesorial y la indígena aymara en la actualidad.

Figura 3: Formatos participativos actuales del conflicto por la propiedad de la tierra (comunidad sucesorial y comunidad indígena).

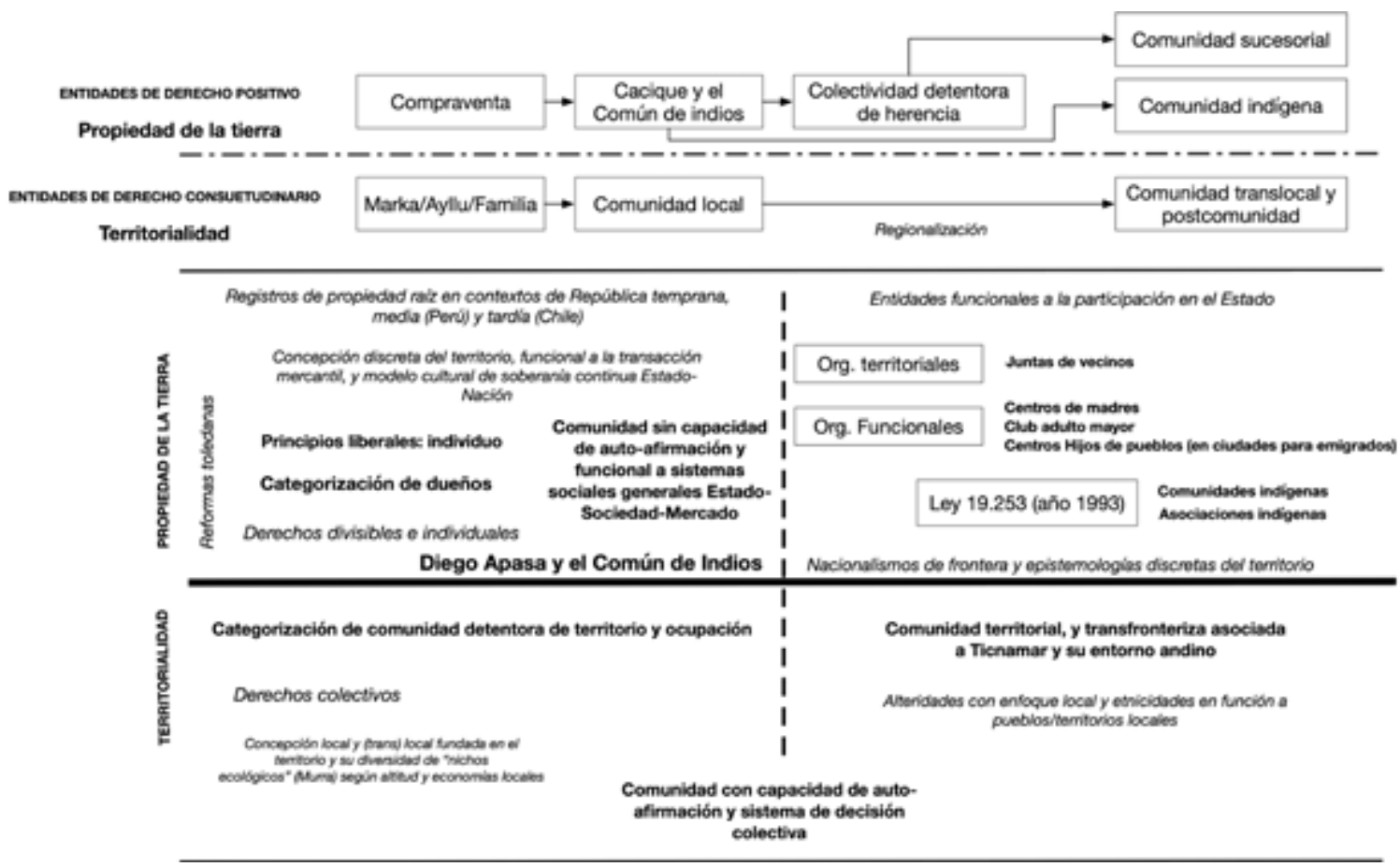

Fuente: Elaboración propia. 
Desde los intereses opuestos, la continuidad de los pleitos sobre acciones y derechos

En 2003, siguiendo el itinerario del conflicto histórico, uno de los miembros de la colectividad detentora de herencia y los cesionarios de los tres ascendientes restantes procuraron practicar un acto de inscripción a su favor, a lo que el Conservador de Bienes Raíces de Arica no accedió, aludiendo que los herederos de 1942 no acreditaron dominio sobre el predio inscrito en 1944. Dado lo anterior, los miembros antes señalados procedieron judicialmente contra el Conservador en el Primer Juzgado de Letras de la misma ciudad, el cual ordenó, en 2005, practicar la inscripción conservatoria solicitada, limitándola a acciones y derechos sobre el predio ${ }^{26}$.

Esta discriminación de "acciones y derechos" referente al estatus de propiedad de la tierra se incorporó de manera novedosa en las pautas del conflicto y en el resguardo de los derechos colectivos. Asimismo, se definió una nueva figura sociojurídica en los detentores de herencia, la comunidad sucesorial, con calidad de comuneros reconocidos por los tribunales de justicia. Con ello se hizo notar un matiz en las acepciones de dominio y una restricción al establecimiento de emergentes fragmentaciones prediales según la vigencia del Decreto Ley 2.695 (1979).

En ese escenario se produjo una serie de eventos que agudizaron la escisión de intereses y la posibilidad de coordinación entre los grupos. Respecto de la comunidad sucesorial se advierten cesiones de derechos que han fragmentado sus acciones y que han derivado en un conflicto sobre la diferenciación entre las acciones y la titularidad de la propiedad raíz. En este aspecto, en 2005, los representantes de esa entidad, amparándose en la inscripción del mismo año, solicitaron al Cuarto Juzgado de Letras de Arica la designación de un administrador pro-indiviso sobre el predio de Ticnamar, tras declararse como comuneros exclusivos de dicho inmueble. El tribunal, luego de varias incidencias ${ }^{27}$ en contra interpuestas por la comunidad indígena aymara ${ }^{28}$, designó al administrador pro-indiviso a través de un Directorio de la Comunidad Sucesorial ${ }^{29}$. La función abordada por esta figura ha sido establecer una representatividad legal y gerencial del bien raíz, que incluye la capacidad para autorizar inversión pública y privada en el territorio.

En 2007, la disputa por el dominio de la propiedad se intensificó. La comunidad indígena interpuso una demanda reivindicatoria sobre las tierras en litigio ${ }^{30}$, en la que abogó por la incorporación de criterios de jurisprudencia indígena contemporánea, cuyo tratamiento se fundamentó en la Ley 19.253 y en el Convenio $169^{31}$ de la Organización Internacional del Trabajo (OIT). En $2012^{32}$, sujetándose al principio de la relación entre pueblo y territorio, la sentencia ratificó la titularidad de Apasa y el común de indios, pero también reconoció las acciones y los derechos de la comunidad sucesorial. Además, anotó que pueden existir más herederos que detenten derechos consuetudinarios, en referencia a los miembros de la comunidad indígena.

Con esta acción, se abrió el espectro formal de detención de derechos. En él se incluyó a un conjunto aglutinado en la apelación a la ocupación ancestral, correspondiente a los descendientes del "común de indios". En consecuencia, en $2014^{33}$, la sentencia de recurso de protección reconoció, de acuerdo con el Convenio 169 de la OIT, derechos de representación a la comunidad indígena sobre las tierras de Ticnamar, invocando el criterio de ocupación ancestral. 
Pese a ello, el esquema de herederos se amplió, ya no en torno al predio como elemento divisible o de disputa, sino que como unidad mayor y garante de un sujeto colectivo que agrupa diferentes sistemas de ocupación, significado, origen y modos de establecimiento de propiedad. Al poner de relieve la continuidad de la ocupación de los grupos y las lógicas extrapapel o basadas en la "costumbre", aparecen como centrales los parámetros de consenso y disenso en la composición sociocultural de los ticnameños y como referentes de la territorialidad local, que integra planos de origen, alterización, arreglos para el acceso a la propiedad colectiva y perspectivas del conflicto intracomunitario (Tabla 2).

Si observamos la tabla 2, en términos de origen, las entidades en disputa por la propiedad comprenden el conflicto como excluyente. Ello porque su alterización viene dada por desencuentros entre facciones de interés en el territorio, a lo que se suma la incorporación de las identificaciones étnicas que amparan, en el fundamento etnogubernamental, oposiciones entre aymara/aymara y quechua/aymara, en las que se ven involucrados los actores locales. Del mismo modo, la controversia se materializa en los diferentes mecanismos asumidos por los grupos para conseguir el acceso a la propiedad de la tierra. Es decir, la comunidad sucesorial reconoce parámetros agnaticios y relativamente unilineales y/o cognaticios centrados en la vinculación de los miembros actuales con los que originalmente participaron en la protocolización de la copia de título de dominio (1903). Por su parte, la comunidad local, en clave de organización indígena amparada por la Ley № 19.253, reconoce que el acceso a la propiedad es de carácter más decididamente cognaticio y bilateral, según su invocación a la figura del "común de indios". Con ello se define el factor de conflicto como una apelación al territorio, sea en cuanto bien raíz exclusivo o en la medida de su fundamentación por parte de un grupo más amplio, con ocupación fronteriza, que autorreconoce su vinculación con Ticnamar y que adiciona a los detentores de herencia y a la comunidad derivada, en genérico, del común de indios.

Tabla 2: Síntesis analítica de modelo folk local sobre las dimensiones fundamentales de la alterización y la conflictividad respecto de la situación de la tierra.

\begin{tabular}{|c|c|c|}
\hline DIMENSIONES & Comunidad sucesorial & Comunidad indígena \\
\hline \multirow[b]{2}{*}{ ORIGEN } & \multirow[b]{2}{*}{ Tramitación sobre la propiedad raíz. } & Ocupación continua en el territorio (trans)fronterizo. \\
\hline & & $\begin{array}{c}\text { Emergencia de la etnogubernamentalidad } \\
\text { y el indígena "situado". }\end{array}$ \\
\hline \multirow[b]{2}{*}{ ALTERIZACIÓN } & $\begin{array}{c}\text { Oposición a la comunidad general en el acceso } \\
\text { a la propiedad raíz. }\end{array}$ & $\begin{array}{l}\text { Definición como aymara y promoción } \\
\text { de tal cosmovisión. }\end{array}$ \\
\hline & $\begin{array}{c}\text { Segmentos reconocidos como aymaras y otros } \\
\text { como quechuas (esta última diferenciación } \\
\text { en menor grado, asociada a un fenómeno } \\
\text { emergente de etnicidad regional). }\end{array}$ & $\begin{array}{l}\text { Intereses de ocupación y tenencia } \\
\text { con autoadscripción aymara. }\end{array}$ \\
\hline $\begin{array}{l}\text { ACCESO } \\
\text { A LA PROPIEDAD }\end{array}$ & $\begin{array}{l}\text { Invocación de criterios unilineales (agnaticios) y } \\
\text { luego cognaticios en las generaciones actuales, } \\
\text { basados en los miembros ascendientes nombra- } \\
\text { dos en la compraventa e inscripción de la tierra. }\end{array}$ & $\begin{array}{l}\text { Invocación a la figura contractual del común de } \\
\text { indios, tendencia cognaticia y bilateral. }\end{array}$ \\
\hline $\begin{array}{l}\text { FACTOR } \\
\text { CONFLICTO }\end{array}$ & $\begin{array}{c}\text { Apelación al territorio como bien raíz adminis- } \\
\text { trable por una comunidad corporativa y suce- } \\
\text { sorial, en exclusivo. }\end{array}$ & $\begin{array}{l}\text { Apelación al territorio como un territorio ances- } \\
\text { tral más que como una propiedad raíz y exclu- } \\
\text { siva de grupos corporativos, involucrando una } \\
\text { invocación hacia el "común de indios". }\end{array}$ \\
\hline
\end{tabular}

Fuente: Elaboración propia. 


\section{Sobre la situación de la tierra y su alterización comunitaria}

Al margen de sostener una versión en detrimento de la otra sobre la situación de la titularidad de la tierra y la conflictividad social en el caso estudiado, podemos constatar que el itinerario de pleitos jurídicos y las sistemáticas intervenciones del Estado (re)formularon intereses encontrados entre la entidad sucesorial y la comunidad indígena, en cuanto formatos contemporáneos de una diferenciación local y de manifestación de alteridades con formulación histórica.

Con antecedentes en la enunciación del territorio según la categorización de propiedad, aquello implicó el tratamiento sinónimo de este como bien raíz en disputa; es decir, referido a pugnas por su uso, goce y disposición. Sin embargo, tal nudo crítico atenuó y soslayó elementos performativos a disposición de los actores, relativos a las lógicas locales de (re) producción y sostenibilidad territorial y a la condición de sujeto colectivo. Esto implicó la generación de alteridades, pautas consuetudinarias de negociación de conflictos y manejos del territorio en la (trans)frontera producidos constantemente por idearios nacionalistas que circunscriben a lo indígena y lo sitúan en pautas de frontera (Castro, 2001, 2006). En tal escenario, las entidades derivadas de estos procesos construyen su alteridad y eso deriva en el establecimiento de un centro, una ubicación y un sentido alter-ego que articula la manera de relacionarse con el entorno contingente (Giménez, 1997, 2006; Morales, 2013; Ruiz, 2009). Dado esto, en Ticnamar, en la exclusión y la oposición de intereses respecto de la otra falange comunitaria, se prolonga una suscripción común y relacional con el pueblo y el territorio andino, lo que complejiza el tejido comuni- tario que se confronta en el nivel siguiente, el de la titularidad de la tierra.

Así, el derecho a la representación y la administración de la propiedad del territorio influencia la reproducción de la colectividad. Esa definición suscitó ámbitos de solidaridad y oposición entre los miembros y actuó también en las configuraciones que adoptaron los formatos participativos soportados en el parentesco segmentario de tipo cognaticio, la memoria local y la alterización con el territorio (Tabla 2; Figura 2). En tal esquema, se incorporan elementos latentes vinculados a la adopción de criterios externos de auto-adscripción indígena mediados por el Estado y su procesamiento de alteridades. Aquello produjo una tensión complementaria que fue ecualizada -en el sentido que le otorga García Canclini (2005)- por los universos de diferenciación de los grupos locales, al otorgar marcos referenciales para su auto-comprensión y reproducción.

En este encuadre, los ticnameños ${ }^{34}$ radicados en los centros metropolitanos litorales del extremo norte del país y/o en la capital nacional, ya con perfiles dislocados del trabajo directo en el sector agropecuario tradicional, sostienen una relación virtual y efectiva con el pueblo. Virtual, pues es esa adscripción la que justifica su reagrupación como organizaciones en las ciudades, insistiendo en la promoción de las costumbres y las festividades, así como en los activos de memoria del ethos comunitario. Efectiva, en la medida que mantienen una relación iterativa entre los centros urbanos y sus residencias/hábitat en el sector de Ticnamar, en invocación a la memoria de sus ascendientes -generalmente sepultados en el cementerio del pueblo- y al establecer arreglos productivos con inmigrantes de sectores de Bolivia o locales para mantener la chacra. Conciben, además, 
la posibilidad de retorno al pueblo después de jubilarse en los centros urbanos (Carrasco, 2016; Cerna y Muñoz, 2019).

Conforme a los antecedentes históricos expuestos, se advierte que el régimen de propiedad de la tierra ha sido un importante modulador de la formación comunitaria al contextualizar el fenómeno de las etnicidades andinas subsecuentes que explican la disputa por intereses jurídicos y por la identificación originaria de la territorialidad local. Siguiendo a García Canclini (2005), este efecto ecualizador opera como un acto de uso y apropiación de diversos elementos culturales, los cuales logran generar una síntesis que resguarda los elementos mínimos de la reproducción del sentido de grupo. En particular, la emergencia de formaciones colectivas diferenciadas, basadas en un arraigo local, ha permitido la (re)producción de la comunidad sociológica en Ticnamar, en términos de cambios y continuidades. En esa elaboración sincrética de su origen sociocultural, vemos que las configuraciones de identificación son excluyentes entre sí, en el sentido que comprenden sistemas relacionales y con cierto grado de autonomía en su autorrepresentación y negociación ante el "otro" local y regional indígena (Arana, 2014; Carrasco, 2016; Gavilán, 2016; González y Ruz, 2015, 2017; Gundermann, 1998; Ruz, 2005).

Desde la época de la instalación de la etnogubernabilidad (es decir, con el retorno a la democracia y la emergencia de políticas públicas para indígenas), las configuraciones identitarias se han compactado con nuevos bríos en las clasificaciones indígenas aymara y quechua chilenas. A partir de esas identificaciones, las facciones pugnan por la legitimidad y la soberanía local respecto de sus etnogénesis e intereses comunitarios, fenómeno que perpetúa la fragmentación del colectivo. Su funcionalidad choca, además, con el proceso anterior de intervención gubernamental asociado a los procesos de chilenización (Castro, 2001, 2006; Gavilán, 2016). Del mismo modo, esta confrontación desplaza e invisibiliza los flujos de otredades transfronterizas -especialmente boliviana y peruana, con circuitos históricos en el área- que operan hasta la actualidad, los cuales forman parte de redes laborales y de parentesco vigentes en el territorio andino del área precordillerana (Cerna, Samit-Oroz \& Véliz, 2018; Cerna \& Muñoz, 2019).

Desde esta perspectiva, es posible sostener que el régimen de propiedad de la tierra ha sido un elemento configurador de los procesos de cohesión y conflicto territorial. Este permitió la elaboración de identidades en progresiva diferenciación interna, lo cual dio base a etnicidades divergentes que en la actualidad emergen entre los miembros -aymara y quechua- de la comunidad, según la categoría excluyente y nominativa de "ser" indígena ante el Estado y su aparato clasificatorio, en el sentido que le otorga Boccara (2007). Sin embargo, las colectividades así vistas reconocen como factor de cohesión el territorio histórico. En un primer aspecto, cabe observar la elaboración de un sistema jurídico de acceso a la propiedad de la tierra, que adiciona memorias con anclaje en la fijación escrita ${ }^{35}$ y en el que se utilizan los dispositivos documentales asequibles -producidos por especialistas y la institucionalidad pública-, que otorgan legitimidad a la instalación de performances autovalidantes. Esto define, a su vez, un escenario restrictivo para la circulación del bien raíz entre miembros con ascendencia local y un sistema de estatus. 
Vemos en el caso en estudio y en el hito que implica la elaboración de imaginarios referidos a la compraventa e inscripción de la propiedad raíz, la manifestación de procesos de diferenciación, externos e internos, que conforman una trayectoria que ha soportado una coherencia basal desde mediados del siglo XVIII hasta el siglo XXI. Esta continuidad demarca la configuración contemporánea de lo comunitario y el conflicto referente a la membresía local. El énfasis mencionado se modula con una situación histórica que reconoce, tempranamente, un derecho colectivo con la compraventa de "Diego Apasa y el común de indios". Asimismo, como un elemento específico de complejización, el proceso de constitución de propiedad y de fragmentación de las acciones en el plano situacional tiene un rol sustantivo.

En la definición de "propiedad" actuó una diferenciación que medió el estatus de los comuneros ante el acceso al bien raíz. Tal constructo trajo como correlato un canal conflictivo y excluyente según la condición de "propietarios", "accionistas" o solo "residentes" vinculados a la continuidad ancestral en la ocupación del área ${ }^{36}$. Aquí, si bien pocas estrategias de dominio corporativo se sostuvieron en el territorio, el caso de Ticnamar destaca de manera excepcional por este tenor.

En tal plano, como parangón, existe otra modalidad similar de corporativismo gestionada en Putre hacia 1910, en la que, siguiendo una estrategia jurídica creativa, una asociación conformada por Juan de Dios Aranda y otros 23 comuneros inscribieron una extensa propiedad raíz (Ruz \& Gálvez, 2003; Ruz \& González, 2014). La conformación de esta propiedad comunitaria y sucesorial quedó a nombre de un grupo de comuneros en particular, situación que, si bien escapó a los principios recíprocos del correlato ayllu/marka -en el sentido culturalista y ecológico que este asume-, hace prevalecer una dimensión colectiva ante el derecho positivo, en un momento donde la normativa no reconocía las propiedades comunitarias. Este caso tiene en común con el estudiado un faccionalismo de las entidades sociocomunitarias que responden a la detención de derechos. Casos similares han sido documentados por diferentes autores, entre los que resaltan el de Socoroma (Castro y Bahamondes, 1987, 1988) y el de Guallatire (disputa de las comunidades sucesoriales de Sorasorane y Puquios). En este último se presenta una situación similar a la de Ticnamar, referida al conflicto por la titularidad y la fragmentación de las organizaciones en torno a la administración del territorio y el pueblo, en la que el Estado ha orquestado un conjunto de situaciones de desencuentro intracomunitario en el área.

Así planteado, es dable concebir, desde el caso de Ticnamar, las estrategias convenidas por los niveles institucionales y organizativos para adicionar certidumbre jurídica sobre el bien raíz. Estas instalan, a la vez, arreglos consuetudinarios que reproducen aspectos del derecho colectivo e individual, y una identificación global e inclusiva que discrimina a quienes son (o no) ticnameños, en un sentido territorial, atendiendo a la definición del territorio como espacio apropiado por la colectividad para garantizar su reproducción y las necesidades materiales y simbólicas (Gavilán, 2016; Giménez, 1997, 2006). En un plano general del área andina, estas observaciones encuentran concordancia con las realizadas por Casaverde (1985), Ossio (1992) y Sendón $(2006,2012)$ en sus estudios etnográficos en la zona centro andina sobre sistemas de propiedad indígena de la tierra y el 
agua, y las organizaciones sociales referentes. Asimismo, está en concordancia con lo señalado por estudios etnográficos actuales del área de Codpa, pueblo con el que Ticnamar ha sostenido un proceso histórico común (Cerna y Muñoz, 2019; Cerna, Samit-Oroz y Véliz, 2018).

En otro aspecto, es importante el dominio como elemento de prolongación comunitaria. La diferenciación con capacidad de reproducción de aspectos asociados de etnicidad sincrética y local se media por tal esfera y su segmentación actual (Albó, 1979; Cerna, Samit \& Fradejas-García, 2013; Larson, 2002; Platt, 1982). Esto ya es rastreable en documentos desde el año 1773, así como la alusión a "originarios" con características particulares vinculados a un territorio/pueblo/chacra, como lo observan también algunos autores (Inostroza, 2017; Véliz, 2014). Desde el sustrato definido por las reformas toledanas, la centralidad del pueblo como unidad socioterritorial resulta relevante. Este constructo elabora la identificación microrregional en pugna, entendida como un sistema de interacción social originado en procesos de imposición de categorías de alteridad e instalación de una frontera semántica propia (Barth, 1976; Gundermann, 1998, 2003, 2005; Morales, 2013).

En esta materia, desde mediados del siglo XX, el dominio se mostró como elemento sustantivo de continuidad a nivel translocal, manteniendo una capacidad de reproducción de la población según la importancia de la dinámica de los hogares y la subjetivación de la pertenencia con el pueblo. A propósito, diferentes estudios han llamado la atención sobre esta relación. Por ejemplo, Abercrombie (2006) lo hace desde un abordaje teórico y Albó (1979) con la alusión a khitipxtansa en el caso aymara boliviano. González, Gundermann \& Hidalgo (2014), desde el recorte del espacio histórico indígena en el extremo norte, han sostenido la importancia de la agencia comunitaria de la sociedad indígena, en la que es fundamental el arraigo en los territorios locales, que es el que conecta la diversidad de experiencias biográficas (ciclos vitales) y memorias colectivas. En este sentido, concordamos con Gundermann (2001, 2003, 2005) respecto de la importancia de la propiedad raíz para la formulación de la acción colectiva andina en el área. La categoría de dominio actuó ahí fragmentando a la comunidad local pero permitiendo también una diferenciación global y corporativa, centrada en elementos de arraigo con la localidad como centro de la experiencia histórica y artefacto de identificación (González y Gundermann, 1997, 2009).

En síntesis, es factible sostener que la emergencia de formaciones colectivas basadas en un arraigo local ha permitido la reproducción sociocultural de la comunidad andina -entendida territorialmente- desde una matriz sincrética en términos socioculturales de origen. El régimen de propiedad de la tierra, en clave de gubernamentalización, configuró, en ese marco, procesos de cohesión y conflicto territorial que permitieron la elaboración de identificaciones y alteridades en progresiva diferenciación y exclusión, que reconocen, como factor de adhesión, el territorio histórico. Aquello ha sido constatado en otros estudios de caso en el área (Castro, 1997, 2001; Castro y Bahamondes, 1987, 1988; Cerna y Muñoz, 2019). Asimismo, el ámbito más general andino es coherente con la observación de identidad localista sostenida por Albó (1979).

Así, la membresía comunitaria, en el caso estudiado, instala un activo inclusivo respecto de las diferenciaciones excluyentes: el terri- 
torio. En cuanto pliegue epistemológico, identitario, jurídico, socioeconómico y cultural, este se encuentra afecto a lógicas de hegemonización en su expresión y contiene emotividades y racionalizaciones situadas que van más allá de las clasificaciones étnicas. Estas distinciones se replican en el campo de la propiedad de la tierra, generando escisiones y convocatorias respecto de la categoría comunitaria de ticnameños (Castro, 2006; Isla, 2017; Krotz, 2002; Salomon, 1991). De este modo, puede revelarse como un lugar de arraigo y/o de negociación de subdivisión de acciones y propiedad raíz -afectas a su introducción en la esfera mercantil. Al hacerlo, expresa elementos de la continuidad histórica de la memoria con base en la invocación de dispositivos escritos/orales y costumbres, los que van agregando elementos de complejización a la organización social referente de la disputa por el bien raíz, en el sentido de aprehender para sí aspectos del territorio ancestral (González \& Ruz, 2015; Gundermann, 2005).

\section{Consideraciones finales}

Desde el estudio de caso de Ticnamar se describió la diferenciación comunitaria relativa al conflicto por la titularidad de la propiedad de la tierra indígena. Rastreando su dimensión histórica hasta la deriva actual del fenómeno, el análisis principal de tipo documental, complementado con una triangulación de información primaria producida por entrevistas a informantes claves y observación participativa, reveló una relación entre la formulación de la diferenciación sociocultural y la trayectoria seguida en la regularización de la propiedad de la tierra. Desde ahí se observó que se conciben alteridades en oposición, de acuerdo con redes de parentesco ancladas en el territorio ancestral. Esta conclu- sión es consistente con otras indagaciones realizadas en otras áreas del sector (Cerna \& Muñoz, 2019; Cerna, Samit-Oroz \& Véliz, 2018; Gundermann, 2005). Es decir, existen similitudes con un proceso que se inicia en el siglo XVIII con la compraventa de tierras y que da paso a una etapa de polarización intracomunitaria hasta el presente, producto de los litigios por el dominio de la tierra en cuanto bien raíz.

En un orden histórico, vemos que se formuló un sistema de propiedad desde la racionalización local (siguiendo elementos positivos y consuetudinarios), que fue proveyendo factores de (re)producción identitaria entre los miembros de la comunidad conforme a la proyección de conflictos locales, a veces irresolubles en la era del multiculturalismo, que sostiene los principios liberales y utilitarios de segmentación y exclusión de la tierra en cuanto propiedad. Sin embargo, en los tiempos por venir probablemente se establezcan nuevas pautas asociadas a la apropiación y masificación del discurso de derechos culturales y territoriales que insta a la reflexividad sobre los parámetros asociados a la continuidad ancestral de la figura de derecho colectivo y a la relatividad del derecho positivo en la mediación por la titularidad de la tierra (Berraondo, 2006).

Para subsiguientes indagaciones sobre este caso y otros en el área en el que se inserta, se estima, en ese esquema, que es relevante documentar la asociación de elementos emergentes de estratificación, fundados en los nuevos contextos neoliberales de inserción de los miembros de estas localidades. En ellos se va inscribiendo una elaboración comunitaria translocal de los contingentes andinos de los "pueblos del interior", así como las pautas de desagrarización que localmente siguieron 
los comuneros y las lógicas de migración de retorno que irán adoptando, como advierte González (2016). Asimismo, importa saber más profundamente sobre las pugnas identitarias y los intereses construidos que ocurren en torno a las alteridades binarizadas desde las clasificaciones gubernamentales en clave de aymara/ quechua o comunidad sucesorial/comunidad indígena, y su vinculación con los referentes de sentido en campos sociales etnogubernamentales. En este contexto, es necesario advertir el sentido de la promoción dada al territorio como realización sociodemocrática y desarrollista en términos de la ecuación Estado/mercado/ sociedad, en un entorno que advierte dos ejes fundamentales de desarrollo local: el turístico y/o el extractivista de recursos naturales.

Por lo anterior, es relevante detenerse en los fundamentos de la organización social indígena respecto de la propiedad de la tierra y los recursos naturales. Tal punto permite comprender la yuxtaposición sociohistórica de los sistemas jurídicos, positivos y consuetudinarios, en el manejo y el establecimiento de la titularidad en torno a la propiedad raíz y a los derechos de aguas, en vista a la reproducción de los esquemas de parentesco y las alteridades locales situadas territorialmente (Assies, Van der Haar \& Hoekema, 2002; Hann, 1998, 2007; Lavigne, 2018). Esto, con objeto de sondear los mecanismos de (re)producción del ethos local a nivel intergeneracional y el sentido de identificación en la época de la etnogubernamentalidad (Boccara, 2007) y del "indio permitido" (Hale, 2004) en espacios signados por drásticos procesos de despoblación, envejecidos y altamente intervenidos por el Estado y funcionales al capitalismo medio y tardío.

\section{Notas}

\footnotetext{
${ }^{1}$ En este caso, vale connotar los casos del Taller de Estudios Andinos, la Consultora ARCOSEN y la Universidad de Tarapacá, que adoptaron estas funciones y elaboraron los primeros informes catastrales del área norte en los contextos del altiplano norte y sur, precordillera y valles.

${ }^{2}$ En invocación al art. 63 de la Ley № 19.253 (año 1993), se señalan los tipos de dominios indígenas ante los procesos de saneamiento y constitución de la propiedad de las comunidades (definidas por la misma ley, mediante su art. 9, de acuerdo a poseer una o más de las siguientes condiciones: provenir de un mismo tronco familiar, reconocer una jefatura tradicional, poseer o haber poseído tierras indígenas en común y/o provenir de un mismo poblado antiguo). Bajo estos términos y considerando las observaciones sostenidas en el catastro base de la década de 1990, denominaremos a las comunidades de tierras, según su situación de dominio y correlato de arreglos para la detención de derechos. Así, las comunidades de tierras individuales hacen relación a tierras que comprenden la casa habitación y terrenos de cultivo y forraje, caracterizadas por la apropiación individual con única detención de derechos; la comunitaria se define por el uso productivo que le dan las comunidades a pampas o laderas de cultivo rotativas, en situación de que existen
}

dos o más individuos en su inscripción de origen, y que se haya afecta a la eventual reclamación de derechos sucesores desde tales miembros; en tanto, las patrimoniales se refieren a la propiedad originalmente inscrita por diferentes miembros de comunidades de tierras, ostentación de dominio que en su principio aditivo involucra varias comunidades ante el uso de pastizales, bofedales, vegas y otros aspectos, tierras generalmente destinadas a la actividad ganadera de auquénidos, donde se incluye una relación compleja con la tierra, involucrando aspectos socioculturales y rituales. Finalmente, está el tipo de propiedad sucesorial, característica de zonas altoandinas, caracterizadas por la situación de que luego de la inscripción original por parte de un solo individuo, existe actualmente una red de miembros que declaran detentar derechos por herencia o compra de derechos, en situación actualizada o no, centrándose en que la relación sea cognaticia o unilineal con el ascendiente que adquirió la propiedad en una época histórica determinada a fines del siglo XIX o en el $\mathrm{XX}$. De esta manera, existen dos fenómenos convergentes. Uno, en la formación de un espacio gubernamentalizado de regulación de la propiedad raíz y la tipología de la propiedad que supone. Dos, producto de los propios procesos sociológicos de las comunidades y de su capacidad de agencia social para establecer el seguimiento 
de los conductos regulares de regulación positiva de la propiedad y el desarrollo de sistemas consuetudinarios complementarios que operan como factores protectores de la colectividad ante la sucesión y uso. Consecuentemente, estas agrupaciones de tierras convergen en los formatos organizativos asociados a los mecanismos participativos con el Estado, incorporando sus diferenciaciones familiares e históricas ante la situación de la propiedad de la tierra (Gundermann, 2001, 2003).

${ }^{3}$ Según datos del Censo de 2017 (INE, 2017), 82\% de la población residente se declara indígena, a lo que debe ponerse en correlato un conjunto de miembros que, si bien radican en otros asentamientos capitales o intermedios, mantienen vínculos locales de tipo simbólico, emotivo y/o de retorno, fundados en el parentesco local y el territorio.

${ }^{4}$ Es posible que este colectivo de indios de la reducción de Ticnamar haya comprado las tierras que comprendían su común, adecuando ese mecanismo para resguardar los espacios comunitarios ocupados por costumbre. Estas tierras, en los albores del virreinato, pudieron ser adquiridas por composición o por merced de tierras por españoles afincados antes en el territorio.

${ }^{5}$ Documento del Conservador de Bienes Raíces de Arica, Fojas 25 vta, № 68, año 1909.

${ }^{6}$ En esta mención, en la época colonial se entiende por "guaico" un espacio o terreno hondo determinado por la nominación de sus sectores. También se tiene la definición que realiza Mamani (2010), quien sostiene que por "wayku", vocablo aymara, es dable comprender "una quebrada arenosa y propensa a convertirse en fango".

${ }^{7}$ Documento del Archivo Nacional, Fojas 187, №173, año 1903.

${ }^{8}$ La protocolización de compraventa del señor juez letrado a Vicente Flores y otros cuenta con el testimonio del título de compraventa de Antonio Velasco, quien es señalado como testigo de la publicación del texto que compone la revisita de 1750 de Codpa (Hidalgo, 1978).

${ }^{9}$ Desde entonces se contó, para la definición de su trayectoria histórica, con acervos como los de la iglesia de Ticnamar Viejo, que data de 1698 , y la mantención del pago de tributo, según las revisitas de 1750 y 1773 (Durston \& Hidalgo, 1997; Inostroza, 2017). En 1813, Ticnamar es mencionado en el padrón de la doctrina de Belén, donde se anotan aspectos del uso y el conflicto comunitario de las tierras en referencia a las autoridades de la colonia (Hidalgo, Arévalo, Marsilli \& Santoro, 1988).

${ }^{10}$ Documento del Archivo Nacional, Fojas 187, № 173, año 1903.

${ }_{11}$ Demetrio Egan fue corregidor del partido de Arica durante el período 1770-1776, representante de la Corona española que tenía la facultad de otorgar títulos de dominio.

12 Documento del Archivo Nacional, Fojas 187, № 173, año 1903.

${ }^{13}$ Aquella toma de posesión se requirió en lengua local. Vale observar, por lo tanto, que se hace mención a un escenario local multiétnico y a políticas de pertinencia cultural desde los dispositivos gubernamentales, los que van, del mismo modo, instalando abordajes hegemónicos hacia la diversidad cultural local (Hidalgo, 1978). Considerado tal asunto, la ocupación aymara aparece como principal y asimilada como alteridad referente de la localidad. Sin embargo, es pertinente preguntarse, siguiendo a Hale (2004), cómo se construye al indígena legítimo y visible territorialmente en esa época por parte de los agentes gubernamentales.

${ }^{14}$ Documento del Archivo Nacional, Fojas 187, № 173, año 1903.

${ }^{15}$ Aquí, el documento más temprano acumula datas de 1835, 1840 y 1846 (Expediente colonial de Padroncillos del Distrito de Codpa, Provincia de Arica, fs. 06.09.10 Legajo № 01, Fondo Histórico, Archivo Regional de Tacna).

${ }^{16}$ Archivo Nacional/Biblioteca Nacional, Registro de Propiedad/ Repositorio diarios. Protocolizado a Fojas 187 № 173 del Registro de Instrumentos Públicos de 1903 del Notario Público de Arica.

${ }^{17}$ Los miembros individualizados en el esquema genealógico son ascendientes históricos identificados en las tramitaciones públicas relativas a la propiedad, por tanto, no actores vigentes hoy en día ni afectos a confidencialidad. Por otro lado, desde ellos se establece la suscripción social y jurídica a la propiedad raíz en el caso de estudio.

${ }^{18}$ Esta solicitud de posesión efectiva de herencia del año 1941 se encuentra en el expediente rol №639-2007. Dicha posesión efectiva se concede a cuatro de los solicitantes y el auto de posesión efectiva se inscribe a Fojas 239 vta. № 196 del Registro de Propiedad del año 1942 del Conservador de Bienes Raíces de Arica.

${ }^{19}$ Comuneros que realizaron la protocolización de la Escritura de Compraventa en 1903 (en expediente rol №639-2007, Conservador de Bienes Raíces de Arica).

${ }^{20}$ Inscripción de título de tierras de Ticnamar del año 1944, Fs. 56 № 55 del Conservador de Bienes Raíces de Arica.

${ }^{21}$ Siguiendo datos censales, la población en el año 1930 fue de 334 habitantes. En 1970, descendió a 288 habitantes. En 1992 se contabilizaban 160 personas y en 2005, 93. En el año 2017, el Censo determinó una población residente en viviendas individuales de 48 personas, 23 hombres y 25 mujeres; 39 de ellas se reconocieron como indígenas. Al respecto, 31 personas se reconocieron como aymaras ( 15 hombres y 16 mujeres) y 8 en la categoría étnica "otros" (2 hombres y 6 mujeres) (INE, 2002, 2017. También censos históricos y datos administrativos. Procesamiento REDATAM 7, desagregación por distrito y viviendas individuales).

22 "Sin información" (1966, 1 de noviembre) Nueva vida ha traído a Ticnamar la acción de varios organismos. La Defensa, Arica, Archivo hemeroteca diarios regionales, Biblioteca Nacional.

${ }^{23}$ La palabra ethos es utilizada en el texto en referencia a una forma común de vida o de comportamiento adoptada por un grupo de individuos que pertenecen a una sociedad. Incluye la emotividad, los referentes de sentido y la capacidad de acción colectiva.

${ }^{24}$ Es relevante mencionar que, desde la iniciativa de los adherentes a la comunidad sucesorial en 2010 , aparece la promoción de una figura organizativa indígena local referente a Ticnamar denominada "comunidad indígena Munay Pata de Ticnamar". En los antecedentes de su constitución en el contexto de la Ley № 19.253, sus dirigentes señalan que: "nuestro trabajo por la reivindicación viene en desarrollo desde el año 2010 cuando solicitamos ser reconocidos como comunidad [...] siendo objetados por la autoridad de ese año" (Declaratoria del pueblo quechua, Región de Arica y Parinacota, 2014). Sin embargo, en 2013 se constituyen como asociación 
indígena urbana de la comuna de Arica, bajo el nombre de asociación indígena quechua "Wakmanta Paqariy", con la misión de visibilizar el patrimonio y la participación quechua en la región. A la fecha han generado iniciativas como la festividad de Inti Raymi "Fiesta del Sol" y el abordaje de la valoración de sitios arqueológicos del horizonte tardío de la prehistoria regional. Del mismo modo, se tiene el caso de la comunidad indígena aymara de La Estrella, constituida en 1998.

${ }^{25}$ Cabe observar que diferentes miembros de los formatos participativos han elaborado documentos sobre las tradiciones y el conflicto de la propiedad de la tierra, estableciendo con ello sus propias versiones de los acontecimientos y sentidos de la historia local. Es importante mencionar los trabajos de Yucra (2002), Véliz \& Véliz (2003), Humire, Nancuante y Véliz (2000), Véliz (2014) y Álvarez $(2010,2014)$. De igual forma, son relevantes los estudios de Aguilera (2007), Chacama, Espinoza y Arévalo (1992), Capetillo (1986), Choque (2013) y Choque y Díaz (2015), que, sin pertenecer a la membresía local, procuran abordarla, dando elementos indicativos de la historia social del pueblo. Del mismo modo, resalta el interés por establecer espacios de divulgación y promoción de activos socioculturales referentes al pueblo de Ticnamar por parte de los colectivos ticnameños. Por un lado, desde 2005, está la experiencia del programa radial "Raíces y costumbres de mi pueblo (Ticnamar)", emitido, cada domingo, por miembros de la comunidad en una radio local de Arica orientada a una audiencia indígena, la Radio Andina, incorporándola así a su audiencia y haciendo alusión a los "pueblos del interior". Por otro lado, está el caso de la asociación indígena social y cultural "Jardín Florido hijos de Ticnamar", que organiza la participación del pueblo en espacios folclóricos y cívicos de giro regional y local.

${ }^{26}$ Inscripción de Acciones y Derechos sobre el predio a título de Diego Apasa y el Común de indios, realizada con fecha 4 de agosto de 2005, a Fojas 3299 № 2089 del Registro de Propiedad del Conservador de Bienes Raíces de Arica. Inscripción de Acciones y derechos del año 2005 en expediente rol № 639-2007, en el mismo Conservador.

${ }^{27}$ Incidencias entre la comunidad sucesorial y la comunidad indígena de Ticnamar. Expediente rol № 639-2007, Conservador de Bienes Raíces de Arica.

${ }^{28}$ Personalidad Jurídica № 24 fojas 115 de la Ley Indígena № 19.253, que reconoce las comunidades socioantropológicas ancestrales anteriores al Estado Chileno otorgada en 1999.

${ }^{29}$ Pro-indiviso de la Comunidad Sucesorial de Ticnamar, del año 2006, en expediente rol № 639-2007, Conservador de Bienes Raíces de Arica.

${ }^{30}$ Causa rol № 639-2007 (Tribunal de Justicia), Juicio ordinario, Código reivindicación, fecha de inicio 18.03.2007, demandante: Comunidad indígena aymara de Ticnamar, demandado: Subieta Tarque Cirilo y otros.

${ }^{31}$ Convenio 169 de la OIT. Vigente en Chile desde el 5 de septiembre de 2009.

${ }^{32}$ Causa rol № 639-2007 (Tribunal de Justicia), Juicio ordinario, Sentencia 29.10.2012.

${ }^{33}$ Recurso de protección 37-2014 (Tribunal de Justicia), Comunidad Sucesorial de Ticnamar contra Entel y la Comunidad Indígena de Ticnamar como tercero coadyuvante. Recurso rechazado porque el demandante no acredita titularidad sobre la propiedad.

${ }^{34}$ En esta categoría se incluye una clasificación local establecida de acuerdo con el grado de residencia en el pueblo. En ella se reconoce distintamente a los residentes, a los radicados en Arica (con experiencia biográfica de residencia histórica, que pueden iterar entre el pueblo y la ciudad) y a los descendientes del pueblo ( $\sin$ experiencia histórica en la localidad, y que pueden tener o no vinculación identitaria). Entre estas categorías caben eventualmente conflictos contextuales.

${ }^{35}$ Esta reformulación del territorio se adiciona a otra anterior, impuesta por el sistema colonial, relacionada con la reducción de indios a pueblos. Desde este hito, se reconoce la configuración actual de las comunidades en unidades socioespaciales de "pueblos". Los formatos de asentamientos resultantes tuvieron como criterio común la fijación de un lugar donde instalar el modelo hispano de pueblo (iglesia, plaza pública) y concentrar la población local (antes, probablemente, dispersa), en base a un reparto de tierras y nombramiento de autoridades (Izko, 1986; Salomon, 1991).

${ }^{36}$ Acá se incluyen actores con matriz sociocultural provenientes de localidades bolivianas y/o peruanas con sustrato indígena aymara, como es el caso de Huachacaya o Curahuara de Carangas, por ejemplo. Estos agentes han establecido relaciones de parentesco real vía alianza con miembros locales, en un orden histórico, lo que los incorpora a la localidad y le delega derechos de usos a su descendencia directa, de acuerdo con la tendencia agnaticia. En este sentido, encontramos una asociación con la clasificación de "forastero" y su mecanismo de inclusión, lo que ha sido observado por diferentes estudios de corte etnohistórico (González, Gundermann \& Hidalgo, 2014; Hidalgo, 1978; Inostroza, 2017). 


\section{Referencias bibliográficas}

Abercrombie, T. (2006). Caminos de la memoria y del poder. Etnografía e historia en una comunidad andina. La Paz: Institut français d'études andines, Instituto de Estudios Bolivianos, Cooperación ASDI-SAREC.

Aguilera, R. (2007). Manejo ancestral del recurso hídrico en comunidades indígenas del sector precordillerano de las provincias de Arica y Parinacota. Arica: Corporación Nacional de Desarrollo Indígena.

Albó, X. (1979). ¿Khitipxtansa? ¿Quiénes somos? Identidad localista, étnica y clasista en los Aymaras de hoy. América indígena, 29(3), 477-527.

Álvarez, E. (2010). Genealogía del Pueblo de Ticnamar 17501885. Arica: Publicación del autor (Propiedad intelectual № 175193). (2014). Genealogía del pueblo de Ticnamar. Arica: Publicación del autor.

Arana, L. (2014). Hacia una perspectiva diacrónica y etnohistórica sobre parentesco andino, linealidad y ayllu. Investigaciones Sociales, 18(32), 177-184.

Assies, W., Van der Haar, G. \& Hoekema, A. J. (2002). Los pueblos indígenas y la reforma del Estado en América Latina. Papeles de Población, (31), 95-115.

Baptista, J. A. (2018). Governmentality. En Callan, H. (Ed.), The International Encyclopedia of Anthropology (pp. 1-19). Londres: John Wiley \& Sons.

Barros, A. (2008). Identidades y propiedades: Transiciones territoriales en el siglo XIX. Estudios Atacameños. Revista de Arqueología y Antropología Surandinas, (35), 119-139.

Barth, F. (1976). Introducción. En Barth, F. (Ed.), Los grupos étnicos y sus fronteras (pp. 9-49). México: Fondo de Cultura Económica.

Berraondo, M. (2006). Pueblos indígenas y derechos territoriales: entre el derecho consuetudinario y el derecho constitucional. En Borja, E. (Ed.), Diversidad cultural: conflicto y derecho. Nuevos horizontes del derecho, de los derechos de los pueblos indígenas en Latinoamérica (pp. 161-192). Valencia: Tirant Lo Blanch.

Boccara, G. (2007). Etnogubernamentalidad. La formación del campo de la salud intercultural en Chile. Chungara, Revista de Antropología Chilena, 39(2), 185-207.

Capetillo, G. (1986). Trabajo, propiedad y medio ambiente en los Andes: tenencia de la tierra en la comunidad de Ticnamar (Tesis inédita para optar al título de profesor de historia). Universidad de Tarapacá, Arica.

Carrasco, A. M. (2016). Aymaras del norte de Chile e inserción urbana. En Pérez-Taylor, R., Muñoz, I. \& Ramírez, A. (Eds.), Antropología del desierto. Paisajes culturales: el norte de México y el norte de Chile (pp. 399-417). México: Instituto de Investigaciones Antropológicas, Centro de Investigaciones sobre América Latina y el Caribe-Universidad Nacional Autónoma de México, Universidad de Tarapacá.

Casaverde, J. (1985). Sistema de propiedad y tenencia de pastos naturales altoandinos. Allpanchis, (25), 271-288.

Castro, M. (1997). Agua, derechos y cultura en los Andes del norte de Chile. Chungara, Revista de Antropología Chilena, 29(1), 63-80. (2001). Identidades emergentes: un desafío para los estudios interculturales. IV Congreso Chileno de Antropología, Santiago.

(2006). Comunidad territorial indígena, gestión de recursos hídricos y derechos colectivos. Congreso Internacional WALIR "Pluralismo legal, reforma hídrica y políticas de reconocimiento", Cusco, Perú.

Castro, M. \& Bahamondes, M. (1987). Cambios en la tenencia de la tierra en un pueblo de la precordillera del Norte de Chile: Socoroma. Revista Chilena de Antropología, (6), 35-57.

(1988). Cambio en la tenencia de la tierra en Socoroma. América Indígena, XLVIII(4), 669-694.

Cerna, C., Samit, S. \& Fradejas-García, I. (2013). Grupos de descendencia y propiedad de la tierra aymara en el altiplano del extremo norte de Chile (Región de Arica y Parinacota). Revista Austral de Ciencias Sociales, (25), 47-69. doi:10.4206/rev.austral. cienc.soc.2013.n25-03

Cerna, C., Samit-Oroz, S. \& Véliz, L. (2018). Alterities, Exchange, Marchantes (Merchants) in the Codpa Valley, Northern Chile, in the mid-20th Century. Antípoda. Revista de Antropología y Arqueología, (32), 125-146. doi:https://doi.org/10.7440/antipoda32.2018.06

Cerna, C. \& Muñoz, W. (2019). Movilidad, parentesco e identificación en el valle de Codpa, norte de Chile. Revista Chungara, Revista de Antropología Chilena, Ahead, 1-14. doi: http://dx.doi. org/10.4067/S0717-73562019005001802

Chacama, J., Espinoza, G. \& Arévalo, P. (1992). Arquitectura religiosa en la sierra y puna de la primera región de Chile. Arica: Universidad de Tarapacá.

Choque, C. (2013). Modesto Mena, un plebiscitario irreductible de Ticnamar. Arica: CONADI.

Choque, C. \& Díaz, A. (2015). El archivo familiar de "Modesto Mena" como tecnología simbólica. Identidades, conflictos y memorias colectivas en los Altos de Arica. Diálogo Andino, (46), 123-142.

Durston, A. \& Hidalgo, J. (1997). La presencia andina en los valles de Arica, siglos XVI-XVIII: casos de regeneración colonial de estructuras archipielágicas. Chungara, Revista de Antropología Chilena, 29(2), 249-273.

Foucault, M. (2004). Securité, territoire, population. Cours au Collège de France. París: Gallimard, Le Seuil.

García Canclini, N. (2005). Hibrid Cultures. Strategies for Entering and Leaving Modernity. Minneapolis: University of Minnesota Press.

Gavilán, V. (2016). Identidades sociales territorializadas. Etnicidad del pueblo aymara en el desierto tarapaqueño del norte de Chile. En Pérez-Taylor, R., Muñoz, I. \& Ramírez, A. (Eds.), Antropología del desierto. Paisajes culturales: el norte de México y el norte de Chile (pp. 453-479). México: Instituto de Investigaciones Antropológicas, Centro 
de Investigaciones sobre América Latina y el Caribe-Universidad Nacional Autónoma de México, Universidad de Tarapacá.

Giménez, G. (1997). Materiales para una teoría de las identidades sociales. Frontera Norte, 9(18), 9-28.

(2006). El debate contemporáneo en torno al concepto de etnicidad. Revista Cultura y Representaciones Sociales. Un espacio para el diálogo transdisciplinario, 1(1), 129-144.

(2016). La economía de las comunidades rurales aymara del desierto del norte de Chile. En Pérez-Taylor, R., Muñoz, I. y Ramírez, A. (Eds.), Antropología del desierto. Paisajes culturales: el norte de México y el norte de Chile (pp. 419-451). México: Instituto de Investigaciones Antropológicas, Centro de Investigaciones sobre América Latina y el Caribe-Universidad Nacional Autónoma de México, Universidad de Tarapacá.

González, H. (2007). Comunidad rural en crisis o comunidad translocalizada entre los aymara del norte de Chile. Actas del $6^{\circ}$ Congreso Chileno de Antropología, Tomo I, 537-550.

González, H. \& Gundermann, H. (1997). Contribución a la historia de la propiedad aymara. Arica: Corporación Nacional de Desarrollo Indígena.

(2009). Acceso a la propiedad de la tierra, comunidad e identidades colectivas entre los aymaras del Norte de Chile (18211930). Chungara, Revista de Antropología Chilena, 41(1), 51-70.

González, H., Gundermann, H. \& Hidalgo, J. (2014). Comunidad indígena y construcción histórica del espacio entre los aymara del norte de Chile. Chungara, Revista de Antropología Chilena, 46(2), 233-246.

González, H., \& Ruz, R. (2015). Fe en el papel: la inscripción del dominio de las tierras de la comunidad en el altiplano chileno. Diálogo Andino, (46), 143-152.

(2017). Propiedad de la tierra indígena en el extremo norte chileno. Historia, contexto y casos. Arica: Universidad de Tarapacá.

Goody, J. (1962). Death, Property, and the Ancestors. A Study of the Mortuory Customs of the Lodagaa of West Africa. Stanford: Stanford University Press.

Grebe, A. M. (1997). Procesos migratorios, identidad étnica y estrategias adaptativas en las culturas indígenas de Chile: una perspectiva preliminar. Revista Chilena de Antropología, (14), 55-68.

Gundermann, H. (1998). Comunidad aymara, identidades colectivas y estados nacionales en los albores del siglo XX. En Rojas, M. (Ed.), A 90 años de los sucesos de la Escuela Santa María de Iquique (pp. 153-181). Santiago: LOM, Dirección de Bibliotecas, Archivos y Museos.

(2001). Procesos regionales y población indígena en el Norte de Chile. Un esquema de análisis con base en la continuidad y los cambios de la comunidad indígena. Estudios Atacameños. Revista de Arqueología y Antropología Surandinas, (21), 89-112.

(2003). La formación del espacio andino en Arica y

Tarapacá. Revista de Historia Indígena, (7), 87-138.

(2005). Comunidad aymara y conflicto interno sobre la tierra en la región de Tarapacá-Chile. Cuadernos Interculturales, 3(5), 43-66.
Hale, C. R. (2004). Rethinking Indigenous Politics in the Era of the "Indio permitido". NACLA Report on the Americas, Report on Race, Part I, 16-21.

Hann, C. M. (1998). The Embeddedness of Property (Introduction). En Hann, C. M. (Ed.), Property Relations. Renewing the Anthropological Traditions (pp. 1-34). Cambridge: Cambridge University Press. (2007). A New Double Movement? Anthropological Perspectives on Property in the Age of Neoliberalism. Socio-Economic Review, (5), 287-318.

Hidalgo, J. (1978). Revisita a los altos de Arica en 1750. Arica: Departamento de Antropología-Universidad del Norte, sede Arica.

Hidalgo, J., Arévalo, P., Marsilli, M. \& Santoro, C. (1988). Padrón de la Doctrina de Belén en 1813: un caso de complementariedad tardía. Arica: Facultad de Estudios Andinos-Universidad de Tarapacá.

Hidalgo, J., Castro, N. \& González, S. (2004). La revisita de Codpa (Altos de Arica) de 1772-73 efectuada por el Corregidor Demetrio Egan. Revista Chungara, Revista de Antropología Chilena, 36(1), 103-204.

Humire, V., Nancuante, V. \& Véliz, L. (2000). Influencias y cambios en la estructura económica andina: estudio de dos pueblos, Timar y Ticnamar entre los años 1930-1970 (Tesis inédita para optar al título de profesor de historia). Universidad de Tarapacá, Arica.

INE (2002). Censo de población 2002. Instituto Nacional de Estadística, Santiago, Chile.

(2017). Censo de población 2017. Instituto Nacional de Estadística, Santiago, Chile.

Inostroza, X. (2017). Familia y vida cotidiana en poblados indígenas rurales. Cacicazgo de Codpa (1774-1820). Meridional. Revista Chilena de Estudios Latinoamericanos, (8), 73-96.

Isla, A. (1984). Sistemi di addattamento socioculturale nelle terre alte a Sud del lago Titicaca. Studi per I'Ecologia del Quaternario, (6), 103-124.

(2017). Derechos en pugna. Disputas en torno a la herencia de una Sayaña en territorio aymara. Chungara, Revista de Antropología Chilena, ahead, 1-12.

Izko, X. (1986). Comunidad andina: persistencia y cambio. Revista Andina, 4(1), 59-99.

Johnson, L. M. (2010). Trail of Story, Traveller's Path. Reflections on Ethnoecology and Landscape. Edmonton: Athabasca University Press.

Krotz, E. (2002). Sociedades, conflictos, cultura y derecho desde una perspectiva antropológica. En Krotz, E. (Ed.), Antropología jurídica: perspectivas socioculturales en el estudio del derecho (pp. 13-49). Barcelona: Anthropos, Universidad Autónoma Metropolitana.

Larson, B. (2002). Indígenas, élites y Estado en la formación de las repúblicas andinas, 1850-1910. Lima: Instituto de Estudios Peruanos.

Lavigne, P. (2018). Land Rights. En Callan, H. (Ed.), The International Encyclopedia of Anthropology (pp. 1-3). Nueva York: John Wiley \& Sons.

Mamani, M. (2010). Estudio de la toponimia: Región de Arica y Parinacota y Región de Tarapacá. Origen y significado de nombres de lugares del norte chileno. Arica: Universidad de Tarapacá

Morales, H. (2013). Construcción social de la etnicidad: Ego y 
Alter en Atacama. Revista Estudios Atacameños, Arqueología y Antropología Surandinas, (46), 145-164.

Muñoz, B. (1999). Derechos de propiedad y pueblos indígenas en Chile. Santiago: Comisión Económica para América Latina y el Caribe (CEPAL).

Ossio, J. M. (1992). Parentesco, reciprocidad y jerarquía en los Andes. Una aproximación a la organización social de la comunidad de Andamarca. Lima: Pontificia Universidad Católica del Perú.

Pedrero, M. (s.f.). El Convenio 169 de la OIT y los desafíos para las políticas públicas en materia de tierras indígenas: análisis y generación de propuestas. (Versión preliminar para discusión interna.) Borrador. Arica, Chile.

Platt, T. (1982). The Role of the Andean Ayllu in the Reproduction of Petty Commodity Regime in Northern Potosí (Bolivia). En Lehmann, D. (Ed.), Ecology and Exchange in the Andes (pp. 27-69). Cambridge: Cambridge University Press.

Ruiz, C. (2009). La alteridad. Casa del Tiempo, IV (25), 99-101.

Ruz, R. (2005). Estado, tierra y la comunidad andina. Algunas notas sobre la constitución de la propiedad de la tierra en la Precordillera chilena. Siglos XIX - XX. Werken, (7), 151-164.

Ruz, R. \& Gálvez, M. (2003). Historia y patrimonio de una localidad precordillerana. Arica: Programa Orígenes, Taller de Investigaciones Culturales TINCU.

Ruz, R. \& González, H. (2014). Estado peruano, liberalismo y tierras indígenas en la precordillera de Arica (1854-1880). Si Somos Americanos. Revista de Estudios Transfronterizos, XIV(1), 41-60.

Salomon, F. (1991). Introducción. Tres enfoques cardinales en los actuales estudios andinos. En Moreno, S. \& Salomon, F. (Eds.), Reproducción y transformación de las sociedades andinas siglos XVI-XX, tomo I (pp. 7-26). Quito: Abya-Yala.
Samit, S., Cerna, C. \& Chávez, P. (2014). De repositorios y de comunidades indígenas como sujetos históricos (Región de Arica y Parinacota, Extremo norte de Chile). Revista Norte Histórico, (1), 129-166.

Sendón, P. (2006). Ecología, ritual y parentesco en los Andes: notas a un debate no perimido. Debate Agrario, (40-41), 273-297. (2012). Estudios de parentesco y organización social en los Andes. En Degregori, C. I., Sendón, P. F. \& Sandoval, P. (Eds.), No hay país más diverso. Compendio de la antropología peruana II (pp. 357-410). Lima: Instituto de Estudios Peruanos.

Véliz, L. (2014). Conflicto intracomunitario por la propiedad de tierras ancestrales en la comunidad de Ticnamar, región de Arica y Parinacota, Chile (Tesis inédita de maestría en antropología). Universidad Católica del Norte, Universidad de Tarapacá, Arica.

Véliz, O. \& Véliz, A. (2003). El árbol florido se mantiene en el tiempo. Arica: Programa Orígenes, Corporación Nacional de Desarrollo Indígena.

Yucra, M. (2002). Ticnamar, su historia y sus tradiciones. Arica: Corporación Nacional de Desarrollo Indígena.

\section{Fuentes}

Archivo Nacional, Santiago.

Registro del Conservador de Bienes Raíces de Arica, Fojas 187, № 173, año 1903; Fojas 25 vta, № 68, año 1909.

Biblioteca Nacional, Santiago.

Hemeroteca de diarios regionales, Archivo Diario La Defensa de Arica, Santiago. 